\title{
Organ-Specific Innate Immune Responses in a Mouse Model of Invasive Candidiasis
}

\author{
Michail S. Lionakis ${ }^{\mathrm{a}}$ Jean K. Lim ${ }^{\mathrm{a}}$ Chyi-Chia Richard Lee ${ }^{\mathrm{b}}$ Philip M. Murphy ${ }^{\mathrm{a}}$ \\ ${ }^{a}$ Molecular Signaling Section, Laboratory of Molecular Immunology, National Institute of Allergy and \\ Infectious Diseases, and ${ }^{\mathrm{b}}$ Laboratory of Pathology, Center for Cancer Research, National Cancer Institute, \\ National Institutes of Health, Bethesda, Md., USA
}

\section{Key Words}

Candidiasis $\cdot$ Cellular immunology $\cdot$ Flow cytometry $\cdot$ Leukocyte trafficking $\cdot$ Macrophages $\cdot$ Neutrophils •

Phagocytes

\begin{abstract}
In a fatal mouse model of invasive candidiasis (IC), fungal burden changes with variable dynamics in the kidney, brain, spleen, and liver and declines in all organs except for the kidney, which inexorably loses function. Since leukocytes are required to control Candida, we hypothesized that differential leukocyte infiltration determines organ-specific outcome of the infection. We defined leukocyte accumulation in the blood, kidney, brain, spleen, and liver after infection using fluorescent-activated cell sorting (FACS) and immunohistochemistry. Accumulation of Ly $6 c^{\text {int }} C D 11 b^{+}$neutrophils predominated in all organs except the brain, where $\mathrm{CD} 45^{\text {int }} \mathrm{CD} 11 \mathrm{~b}^{+} \mathrm{CD} 11 \mathrm{c}^{-}$microglia were the major leukocytes detected, surrounding foci of invading Candida. Significantly more neutrophils accumulated in the spleen and liver than in the kidney during the first $24 \mathrm{~h}$ after infection, when neutrophil presence is critical for Candida control. Conversely, at later time points only the kidney continued to accumulate neutrophils, associated with immunopathology and organ failure. The distribution of neutrophils was completely different in each organ, with large abscesses exclusively forming in the kidney. Candida filamentation, an essential viru-
\end{abstract}

lence factor, was seen in the kidney but not in the spleen or liver. IC induced Ly $6 \mathrm{c}^{\text {hi }} \mathrm{CD} 11 \mathrm{~b}^{+}$inflammatory monocyte and $\mathrm{NK} 1.1^{+}$cell expansion in the blood and all organs tested, and $\mathrm{MHClI}^{+} \mathrm{F} 4 / 80^{+} \mathrm{CD}_{11 \mathrm{C}^{-}}$macrophage accumulation, mainly in the spleen and liver. This study is the first detailed analysis of leukocyte subsets accumulating in different target organs during IC. The results delineate immune responses to the same pathogen that are highly idiosyncratic for each organ tested. The work provides novel insights into the balance between effective host defense and immunopathology in IC.

Copyright $\odot 2010$ S. Karger AG, Basel

\section{Introduction}

Invasive candidiasis (IC), mainly caused by Candida albicans, is the fourth leading cause of nosocomial bloodstream infection in the US, with an incidence of 30/ 100,000 patient admissions and an annual estimated cost of 1 billion dollars [1]. In patients who develop IC, mortality exceeds $40 \%$ despite the use of potent antifungal

Presented in part at the 49th Interscience Conference on Antimicrobial Agents and Chemotherapy, San Francisco, September 12-15, 2009 (late-breaker abstract M-1696b) and at the 50th Interscience Conference on Antimicrobial Agents and Chemotherapy, Boston, September 12-15, 2010 (abstract M-1076).

\section{KARGER}

() 2010 S. Karger AG, Basel

Fax +41613061234

E-Mail karger@karger.ch

www.karger.com
Accessible online at: www.karger.com/jin
Dr. Philip M. Murphy

Molecular Signaling Section, Laboratory of Molecular Immunology

National Institutes of Health, Building 10, Room 11N113, 9000 Rockville Pike Bethesda, MD 20892 (USA)

Tel. +1 301496 8616, Fax +1 301402 4369, E-Mail pmm@ nih.gov 
therapy [1]. Thus, IC represents a major unsolved medical problem in which better understanding of its immunopathogenesis and identification of new therapeutic targets are needed.

The systemic mouse model of IC mimics human bloodstream-derived disseminated candidiasis and has been used extensively to study host defense and antifungal drug efficacy in this condition [2-4]. In this model, despite dissemination and presence of Candida in all tissues, some organs, such as the kidney, exhibit continuously increasing fungal burden after infection, whereas in other organs, such as the spleen and liver, fungal burden declines [2,3]. Yet, the cellular and molecular factors that determine differential organ-specific control of Candida remain largely unknown.

Although a comprehensive tissue-specific analysis of the cellular immune response in IC is lacking, studies in the mouse model have clearly established the importance of phagocytes in anti-Candida host defense. Specifically, neutrophils and macrophages phagocytose and kill Candida, and depletion of either immune cell subset results in increased tissue fungal burden and accelerated mortality [5-8]. Nonetheless, organ-specific differences in phagocyte-mediated protection against Candida do exist. Thus, whereas neutrophil depletion impairs control of Candida proliferation in the kidney, heart, spleen and liver, fungal burden in the blood and brain is unaffected $[5,6]$. Of the remaining innate immune cells, the role of inflammatory monocytes and natural killer $(\mathrm{NK}), \mathrm{NK} \mathrm{T}(\mathrm{NKT}), \gamma \delta \mathrm{T}$ and dendritic cells in antiCandida host defense has not been defined in vivo. In stark contrast to the requirement for innate immunity in host defense against IC, the adaptive immune arm is dispensable. Thus, mice with severe combined immunodeficiency that lack functional $\mathrm{T}$ and $\mathrm{B}$ cells do not have increased mortality following systemic infection with C. albicans [9].

Because leukocytes accumulate at sites of Candida infection and can kill the organism [10], we reasoned that tissue-specific patterns of leukocyte infiltration might determine regional differences in the outcome of IC. To test this, we defined the temporal and spatial accumulation of all major leukocyte subtypes (neutrophils, inflammatory monocytes, macrophages, brain microglia, NK cells, NKT cells, $\gamma \delta$ T cells, CD 4 and CD8 $\mathrm{T}$ lymphocytes, B lymphocytes, and dendritic cells) in the blood, kidney, brain, spleen, and liver of control uninfected and Candida-infected C57Bl/6 mice using fluorescent-activated cell sorting (FACS) and immunohistochemistry (IHC).

Organ-Specific Innate Immune

Responses in Invasive Candidiasis

\section{Materials and Methods}

Mouse Model of IC

We used 8-week-old female C57Bl/6 mice from Taconic Farms (Germantown, N.Y., USA) for all experiments under the auspices of a protocol approved by the Animal Care and Use Committee of the National Institute of Allergy and Infectious Diseases. Mice were injected via the lateral tail vein with 2.5 or $5 \times 10^{5}$ blastospores of C. albicans SC5314 (a gift from Dr. John Bennett, NIH), an inoculum that causes $100 \%$ mortality by day 10 after infection. Candida was grown at $30^{\circ} \mathrm{C}$ in yeast extract, peptone, and dextrose (YPD) medium containing penicillin and streptomycin (Mediatech, Herndon, Va., USA). Cells were centrifuged, washed in phosphate-buffered saline (PBS), and counted using a hemocytometer.

\section{Determination of Fungal Burden}

Infected mice were euthanized $15 \mathrm{~min}, 1 \mathrm{~h}$, and 1,4 , and 7 days after infection ( $\mathrm{n}=4 \mathrm{mice} / \mathrm{time}$ point) to determine the fungal burden in the blood, kidney, brain, spleen, and liver. Blood (300 $\mu \mathrm{l})$ obtained via cardiac puncture was plated on YPD agar plates containing penicillin and streptomycin. The organs were aseptically removed, weighed, homogenized in PBS, serially diluted, and plated in duplicate on YPD agar plates containing penicillin and streptomycin. Colony-forming units (CFUs) were determined after $48 \mathrm{~h}$ of incubation at $37^{\circ} \mathrm{C}$ and results were expressed as CFUs/g tissue or ml blood [3].

\section{Histopathological and IHC Studies}

Control uninfected mice and infected mice were euthanized on days 1,4 , and 7 after infection ( $\mathrm{n}=3$ mice/time point), and the kidney, brain, spleen, and liver were removed, fixed with $10 \%$ formalin and embedded in paraffin wax. Tissue sections were stained with periodic acid-Schiff (PAS) or placed on poly-L-lysine-coated glass slides, deparaffinized in xylene and rehydrated in a graded series of alcohol. Following antigen retrieval for $20 \mathrm{~min}$ at $85^{\circ} \mathrm{C}$, endogenous peroxidase was blocked by alcohol containing $0.3 \%$ hydrogen peroxide for $10 \mathrm{~min}$ at room temperature (RT). The slides were incubated with $5 \%$ bovine serum albumin (BSA; Sigma-Aldrich, St. Louis, Mo., USA) for $20 \mathrm{~min}$ to block nonspecific protein binding sites. After washing with Tris-buffered saline containing $0.05 \%$ Tween 20, rat anti-mouse 7/4 (1:10; Cedarlane Laboratories, Burlington, N.C., USA) [11], goat anti-mouse NKp46 (1:100; R\&D Systems, Minneapolis, Minn., USA) [12], or rabbit anti-mouse Iba1 primary antibody (1:100; Wako Chemicals, Richmond, Va., USA) [13] was added in 1\% BSA, and slides were incubated overnight at RT. BSA (1\%) without primary antibody was used as negative control. The slides were then washed twice with Tris-buffered saline containing $0.05 \%$ Tween 20 , and detection of immunoreaction was achieved using the streptavidin-horse radish peroxidase system (Dako, Carpinteria, Calif., USA) containing the streptavidin-peroxidase complex after a 30-min incubation at RT. Color was developed with 3,3'diaminobenzidine (Dako) and hydrogen peroxide (Sigma), and slides were subsequently counterstained with hematoxylin, dehydrated, and mounted. Two different sections of each organ per time point were tested per experiment. 
Single-Cell Suspension from Blood and Organs

Control uninfected mice and infected mice were euthanized on days 1,4 , and 7 after infection ( $\mathrm{n}=3$ mice/time point). Mice were anesthetized using ketamine/xylazine and $300 \mu \mathrm{l}$ of blood were obtained via cardiac puncture. Then, the animals were perfused with normal saline and organs were harvested. Single-cell suspensions were obtained using previously described methods $[14,15]$. In brief, anti-coagulated peripheral blood was treated with lysing buffer (BD Biosciences, San Jose, Calif., USA) to remove red blood cells. Then, leukocytes were washed three times with HBSS $+2 \mathrm{mM}$ EDTA $+1 \%$ BSA, suspended in PBS, and passed through a $40-\mu \mathrm{m}$ filter (BD Biosciences). Brains were collected in $7 \mathrm{ml}$ of FACS buffer $\left(\mathrm{PBS}+0.5 \% \mathrm{BSA}+0.1 \% \mathrm{NaN}_{3}\right)$ and homogenized using the plunger portion of a $12-\mathrm{ml}$ syringe in a Petri dish at $4^{\circ} \mathrm{C}$. The suspension was brought to $10 \mathrm{ml}$ by adding $3 \mathrm{ml}$ of $90 \%$ Percoll (GE Healthcare, Piscataway, N.J., USA) in PBS. Then, the suspension was underlaid with $1 \mathrm{ml}$ of $70 \%$ Percoll and centrifuged at $2,450 \mathrm{rpm}$ for $20 \mathrm{~min}$ at $4^{\circ} \mathrm{C}$. The leukocytes at the interphase were isolated, washed three times in FACS buffer, suspended in PBS, and passed through a $40-\mu \mathrm{m}$ filter. Spleens were finely minced and digested at $37^{\circ} \mathrm{C}$ in digestion solution (RPMI 1640 with $20 \mathrm{mM}$ HEPES without serum) containing $0.2 \mathrm{mg} / \mathrm{ml}$ of Liberace CI (Roche Diagnostics, Chicago, Ill., USA) and 300 $\mathrm{U} / \mathrm{ml}$ of grade II DNAse I (Roche) for $20 \mathrm{~min}$ with intermittent shaking. Digested tissue was passed through a $100-\mu \mathrm{m}$ filter, washed, and the remaining red cells were lysed with ACK lysing buffer (Lonza, Walkersville, Md., USA) for $30 \mathrm{~s}$. Then, cells were passed through a $70-\mu \mathrm{m}$ filter and washed three times with FACS buffer. Finally, splenocytes were suspended in PBS and passed through a $40-\mu \mathrm{m}$ filter. To obtain kidney and liver single-cell suspensions, the organs were finely minced and digested at $37^{\circ} \mathrm{C}$ in digestion solution containing $0.4 \mathrm{mg} / \mathrm{ml}$ of Liberace CI and 300 $\mathrm{U} / \mathrm{ml}$ of grade II DNAse I for $20 \mathrm{~min}$ with intermittent shaking. Digested tissue was passed through a $70-\mu \mathrm{m}$ filter, washed, and the remaining red cells were lysed with ACK lysing buffer for $30 \mathrm{~s}$. Then, the cells were passed through a $40-\mu \mathrm{m}$ filter, washed, and suspended in $8 \mathrm{ml}$ of $40 \%$ Percoll. The suspension was overlaid on $3 \mathrm{ml}$ of $70 \%$ Percoll and centrifuged at 2,000 rpm for $30 \mathrm{~min}$ at RT. The leukocytes at the interphase were isolated, washed three times in FACS buffer, suspended in PBS, and passed though a $40-\mu \mathrm{m}$ filter.

\section{Quantification of Leukocytes}

From the blood, kidney, brain, spleen, and liver single-cell suspensions, $100 \mu \mathrm{l}$ each were fixed with $100 \mu \mathrm{l}$ of $2 \%$ paraformaldehyde (USB, Cleveland, Ohio, USA) for leukocyte quantification using PE-conjugated fluorescent particles (Spherotech, Lake Forest, Ill., USA).

\section{FACS}

From the blood, kidney, brain, spleen, and liver single-cell suspensions, $500 \mu \mathrm{l}$ each were stained with a Live/Dead fluorescent dye (Invitrogen, Carlsbad, Calif., USA) for $10 \mathrm{~min}$ (1:500) and then incubated with rat anti-mouse CD16/32 (2.4G2; BD Biosciences) for $10 \mathrm{~min}(1: 100)$ at $4^{\circ} \mathrm{C}$ to block Fc receptors. Then, cells were incubated at $4^{\circ} \mathrm{C}$ for $30 \mathrm{~min}$ with the following antibodies: FITC-conjugated anti-mouse Ly6c (AL-21), CD3 (17A2), NK1.1 (PK136; BD Biosciences), and MHC II (M5/114.15.2; eBioscience, San Diego, Calif., USA); PE-conjugated anti-mouse CD45 (Ly-5) and $\gamma \delta$ T-cell receptor (GL3; BD Biosciences); PE-Cy7-conjugated anti-mouse CD45 (Ly-5; BD Biosciences), CD8 (53-6.7), and F4/80 (BM8; eBioscience); APC-conjugated anti-mouse CD45 (Ly-5), CD11c (HL3; BD Biosciences), and CD19 (1D3; eBioscience); APC-Cy7-conjugated anti-mouse CD11b (M1/70) and CD3 (17A2; BD Biosciences), and APC-fluor-780-conjugated anti-mouse CD4 (RM4-5; eBioscience). After three washes with FACS buffer, cells were fixed with $2 \%$ paraformaldehyde. FACS was performed on an LSRII (BD Biosciences) and data were analyzed using FlowJo software (version 8.8.4; Treestar, Ashland, Oreg., USA).

\section{Results}

\section{Fungal Burden Progression Differs Substantially among Organs in IC}

Intravenous Candida challenge led to inoculum-dependent mortality (fig. 1a), and rapid clearance of $>99 \%$ of the fungus from the bloodstream, with dissemination to all organs tested within the 1 st $h$ after injection (fig. $1 b$ ). Nonetheless, the microbiological progression of IC differed substantially among organs. Specifically, while fungal burden declined in the spleen and liver after infection, the initial fungal burden in the kidney and brain increased (fig. 1b). Even between the kidney and the brain, a distinct pattern was apparent; fungal burden in the brain peaked on day 4 and then declined by day 7 , whereas the kidney fungal burden continued to increase inexorably, $\sim 100$-fold throughout the time course of the experiment (fig. 1b).

Because the kidney was the only organ in which fungal burden did not decline, and since renal blood flow comprises $\sim 25 \%$ of cardiac output [16], we first determined whether the kidney-specific increase in fungal burden could be explained by a larger initial delivery of Candida load to the kidney compared to other organs. As shown in figure $1 \mathrm{~b}$, initial fungal load delivered to the organs did not account for the differences in their subsequent fungal dynamics. As an extreme example, initial Candida load delivered to the kidney and liver at $1 \mathrm{~h}$ (or $15 \mathrm{~min}$ after infection, data not shown) was almost identical, but these organs had $\sim 4$-log difference in fungal burden by day 7 after infection.

\section{Neutrophils, Monocytes and NK Cells Expand in the \\ Blood after Systemic Candida Infection}

We considered that innate immune responses may be very different among organs in the model, and determine the differences in the fungal dynamics we observed. We therefore characterized the temporal and spatial patterns of leukocyte accumulation in the model. Thus, blood, kidney, brain, spleen, and liver were collected at an early 


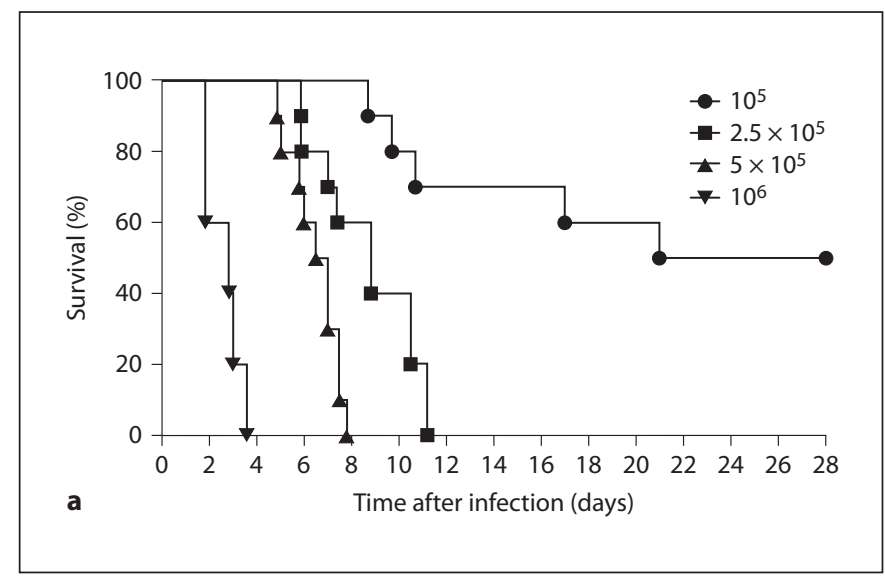

Fig. 1. Fatal mouse model of systemic IC. Inoculum, $5 \times 10^{5} \mathrm{CFU}$. a Mortality of mice intravenously injected with $C$. albicans is inoculum dependent. The inocula/mouse tested are given in the upper right-hand corner of the figure as CFU. b Microbiological pro-

(day 1), intermediate (day 4), and late (day 7) time point after infection and compared to uninfected control mice. FACS analysis of peripheral blood showed that Candida infection induced robust neutrophilia with Ly $6 c^{\text {int }} \mathrm{CD} 11 b^{+}$neutrophils being the predominant leukocytes accumulating in blood ( $>75 \%$; fig. $2 \mathrm{a})$, consistent with previous reports [6]. Of note, $\mathrm{Ly} 6 \mathrm{c}^{\mathrm{int}} \mathrm{CD} 11 \mathrm{~b}^{+}$neutrophils expanded in a continuously increasing fashion in the blood throughout the course of IC and peaked at $>7$ $\times 10^{6}$ cells $/ \mathrm{ml}$ of blood on day 7 after infection, representing an $\sim 100$-fold increase over the uninfected state. $\mathrm{NK}$ cells $\left(\mathrm{NK}_{1.1^{+}}, \mathrm{CD}^{-}\right)$and $\mathrm{Ly}^{\mathrm{C}} \mathrm{c}^{\mathrm{hi}} \mathrm{CD} 11 \mathrm{~b}^{+}$inflammatory monocytes also accumulated, peaking on day 4 (fig. 2a, b), whereas increases in NKT cells, and CD4 and CD8 $\mathrm{T}$ and $\mathrm{B}$ cells did not occur until at least day 4 after infection (fig. 2b). These data demonstrate that systemic Candida infection causes pan-leukocytosis with differential dynamics and neutrophil predominance.

\section{Delayed but Persistent Neutrophil Accumulation in} the Kidney Is Associated with Immunopathology and Unabated Candida Hyphal Growth

We first performed IHC in Candida-infected kidneys using the $7 / 4$ monoclonal antibody, which recognizes mouse neutrophils and monocytes/macrophages [10, 11]. $7 / 4^{+}$cells were not detected before infection, but began to accumulate early after infection in the renal cortex, where they organized into abscesses. At later time points, the inflammatory process spread to the renal tubules and pelvis with an accumulation of massive numbers of $7 / 4^{+}$

Organ-Specific Innate Immune

Responses in Invasive Candidiasis

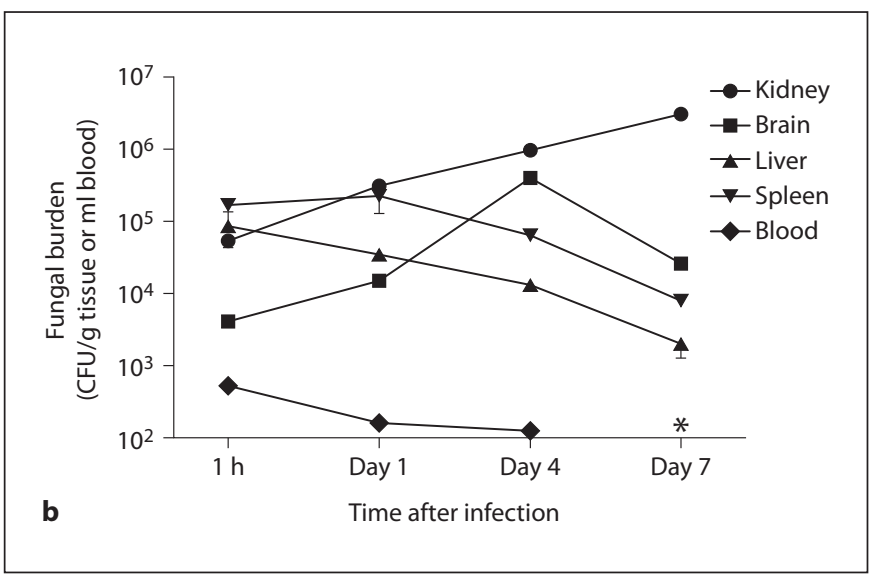

gression of IC is highly variable among tissues. Data are from a single experiment with 4 mice per time point. Graphed are the mean \pm SEM data. The asterisk (day 7) denotes that fungal burden in blood was below the limit of detection at this time point.

phagocytes, tubular cast formation, papillary necrosis, and distortion of the renal architecture with kidney enlargement (fig. 3a). Conversely, the glomeruli were spared throughout the course of IC (fig. 3a, b). Both neutrophils and mononuclear phagocytes comprised the $7 / 4^{+}$cells infiltrating the kidney throughout the infection. Candida filamentation was detected on day 1 after infection in the renal cortex, and the number of hyphae continued to increase throughout the entire course of the experiment and extended to the renal tubules and pelvis. Candida colocalized with phagocytes within cortical and tubular abscesses at all time points tested (fig. 3b).

Next we defined the specific identity of phagocytes accumulating in the infected kidney by immunophenotype using FACS. Ly $6 c^{\text {int }} \mathrm{CD} 11 \mathrm{~b}^{+}$neutrophils were the predominant infiltrating leukocytes in the kidney. Although early neutrophil accumulation was sluggish $(<200,000 /$ kidney on day 1$),>2 \times 10^{6}$ neutrophils $\left(>60 \%\right.$ of $\mathrm{CD} 45^{+}$cells) were found per kidney by day 7 , representing an $\sim 2,000$-fold increase over the uninfected kidney, where only $\sim 1,000$ neutrophils are found (fig. 3c). Ly6 $\mathrm{c}^{\text {hi }} \mathrm{CD} 11 \mathrm{~b}^{+}$monocytes were not found in the uninfected kidney, but accumulated transiently after infection, peaking early on day 1 ( $\sim 25 \%$ of $\mathrm{CD} 45^{+}$leukocytes); the kidney was the only organ in which the ratio of infiltrating monocytes:neutrophils was $\sim 1: 1$ at this time point (fig. 3c); in all other organs, substantially larger numbers of neutrophils over monocytes accumulated on day 1 . On day 7 after infection, $L y 6 c^{\text {hi }} C D 11 b^{+}$ monocytes could no longer be detected. Conversely, 

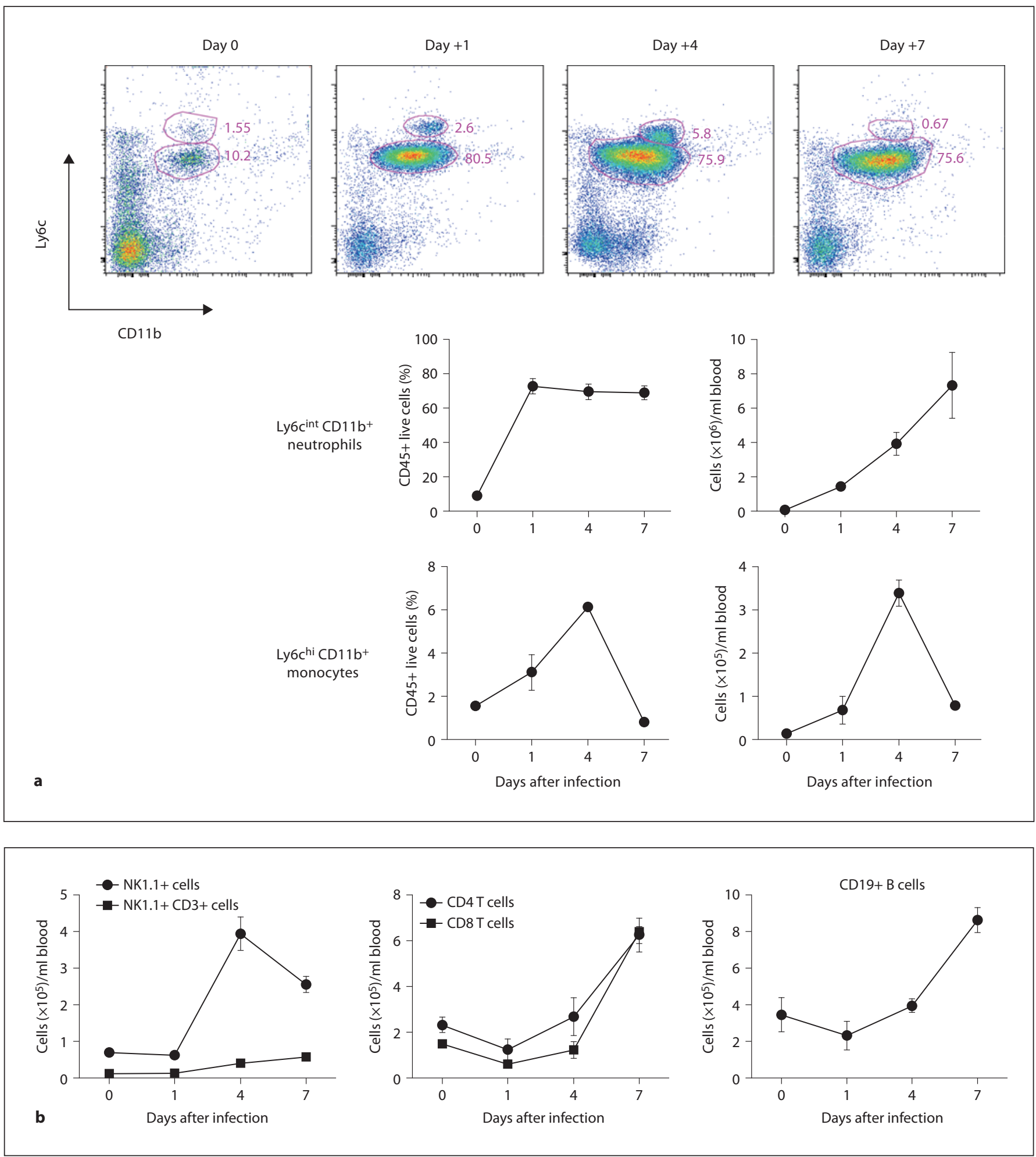

Fig. 2. Dynamics of leukocyte accumulation in blood in a fatal mouse model of systemic IC. Inoculum, $2.5 \times 10^{5} \mathrm{CFU}$. a Representative FACS plots of blood neutrophils and inflammatory monocytes at different time points after infection and in the uninfected state. Graphs show neutrophils and monocytes as percent of $\mathrm{CD} 45^{+}$cells, and as absolute numbers per milliliter of blood. b Accumulation of NK1.1 $1^{+}$cells, $\mathrm{T}$ and B lymphocytes in blood after IC. Data are from a single FACS experiment with 3 mice per time point. Graphed are the mean \pm SEM data. 

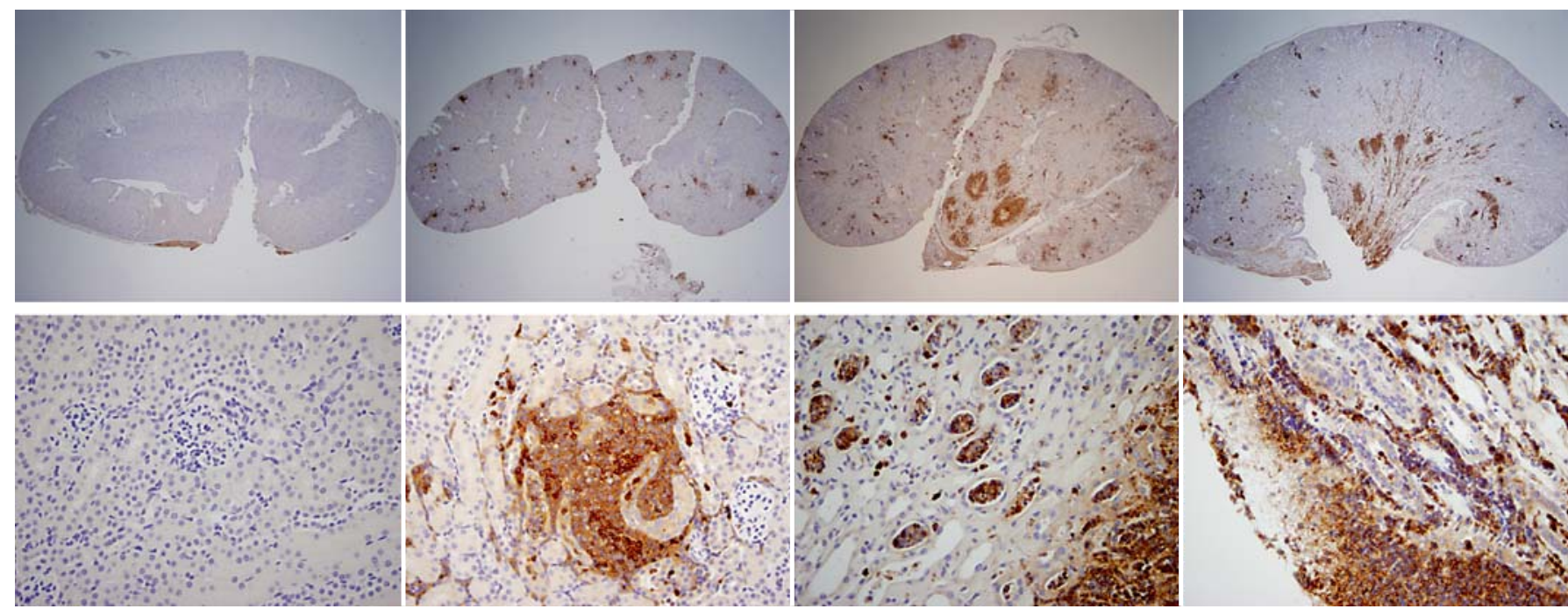

Uninfected

a

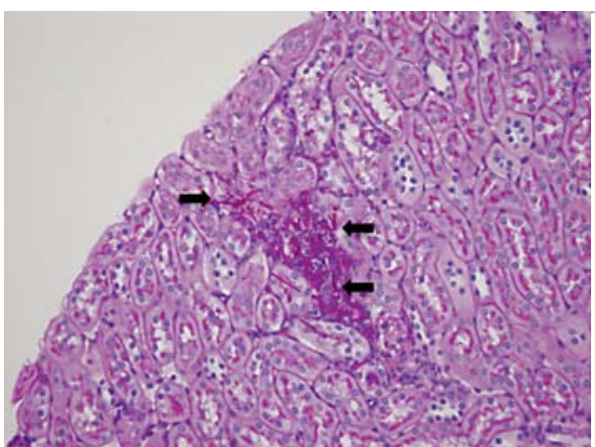

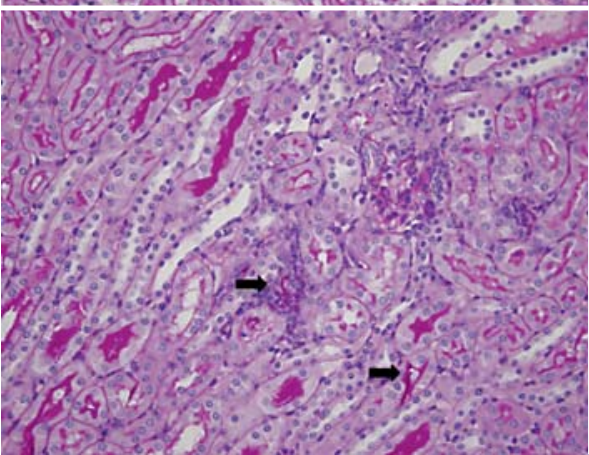

1

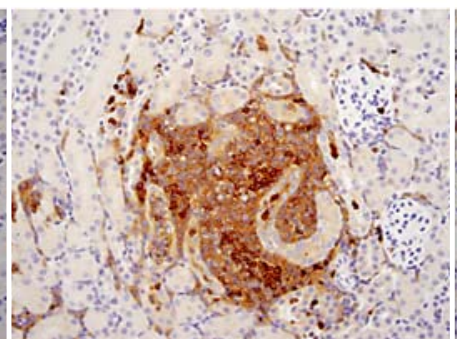

1

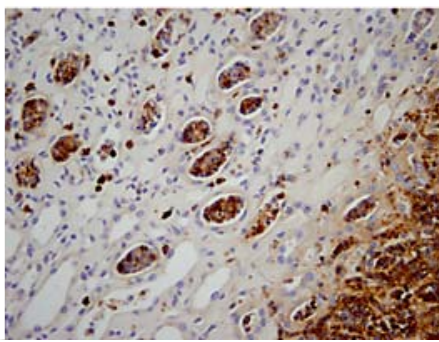

4

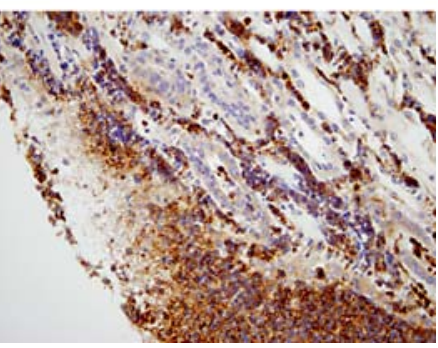

7

Time after infection (days)
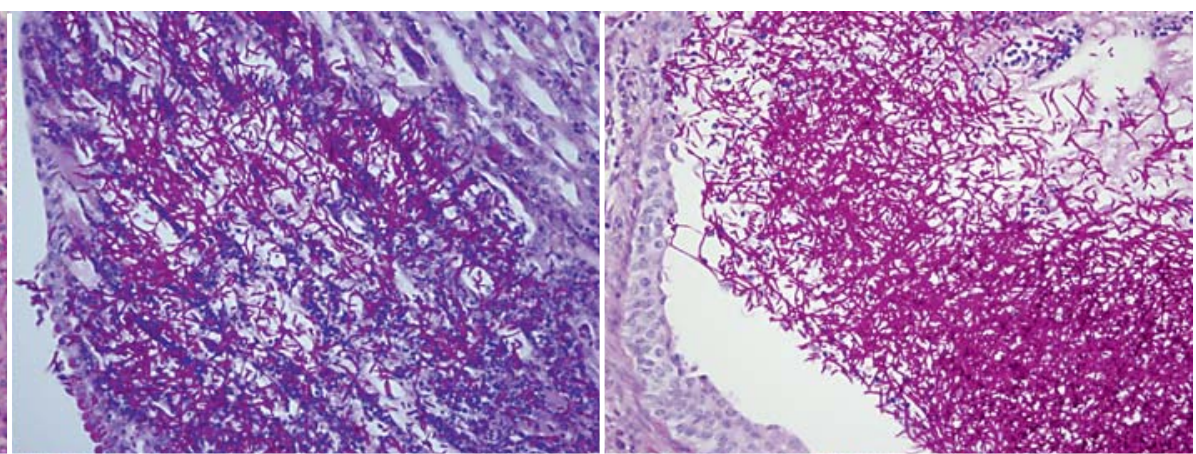

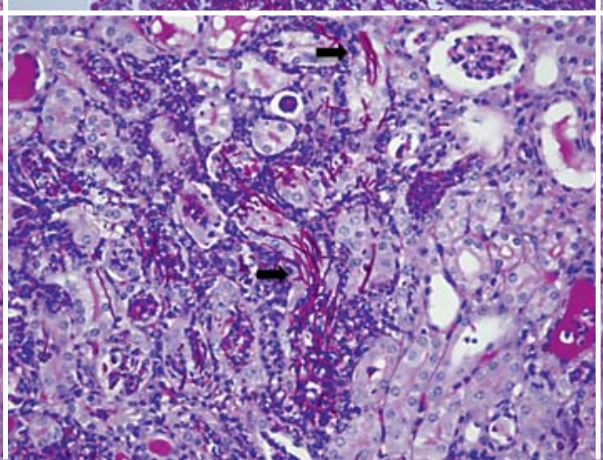

4

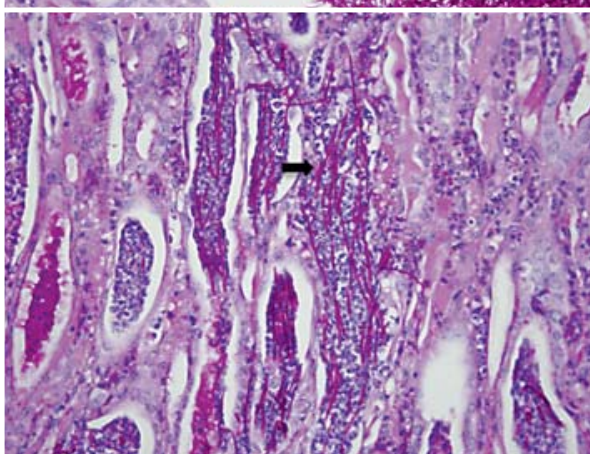

7

Time after infection (days)

Fig. 3. Kidney-specific cellular immune response in a fatal mouse model of systemic IC. Inoculum, $2.5 \times 10^{5}$ CFU. a Representative $7 / 4^{+}$IHC images from kidney cross-sections at different time points after infection. Original magnifications: $\times 20$ (top row) and $\times 400$ (bottom row). Brown color represents $7 / 4^{+}$immune cells. b Representative PAS staining of the kidney at different time points after infection. Original magnification: $\times 400$. Arrows point to representative Candida hyphae. 

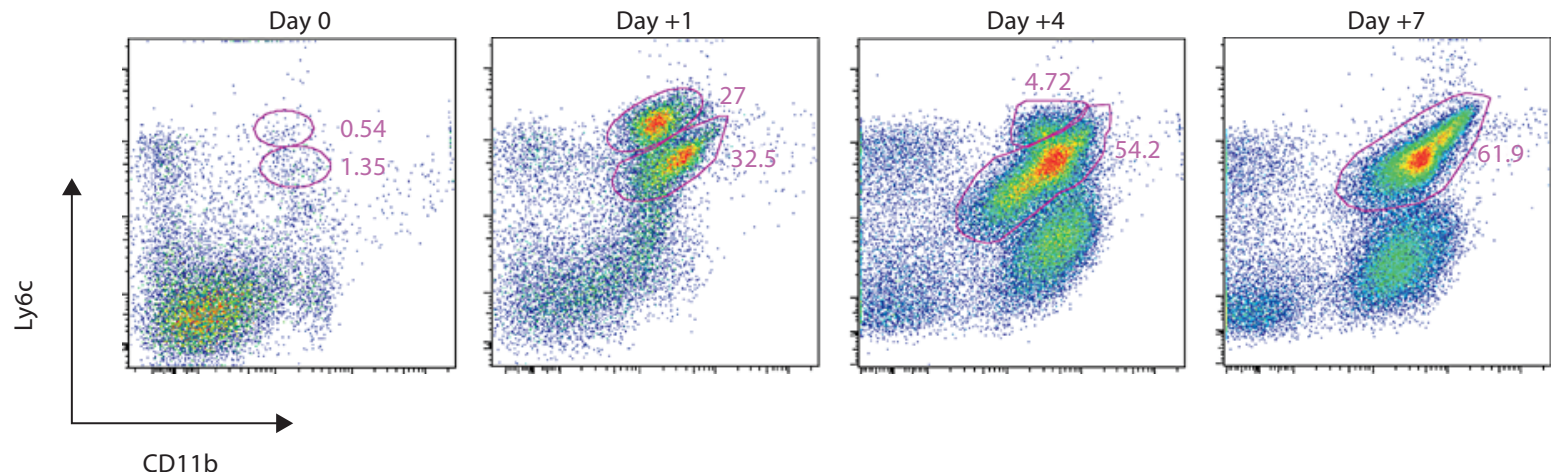

CD11b
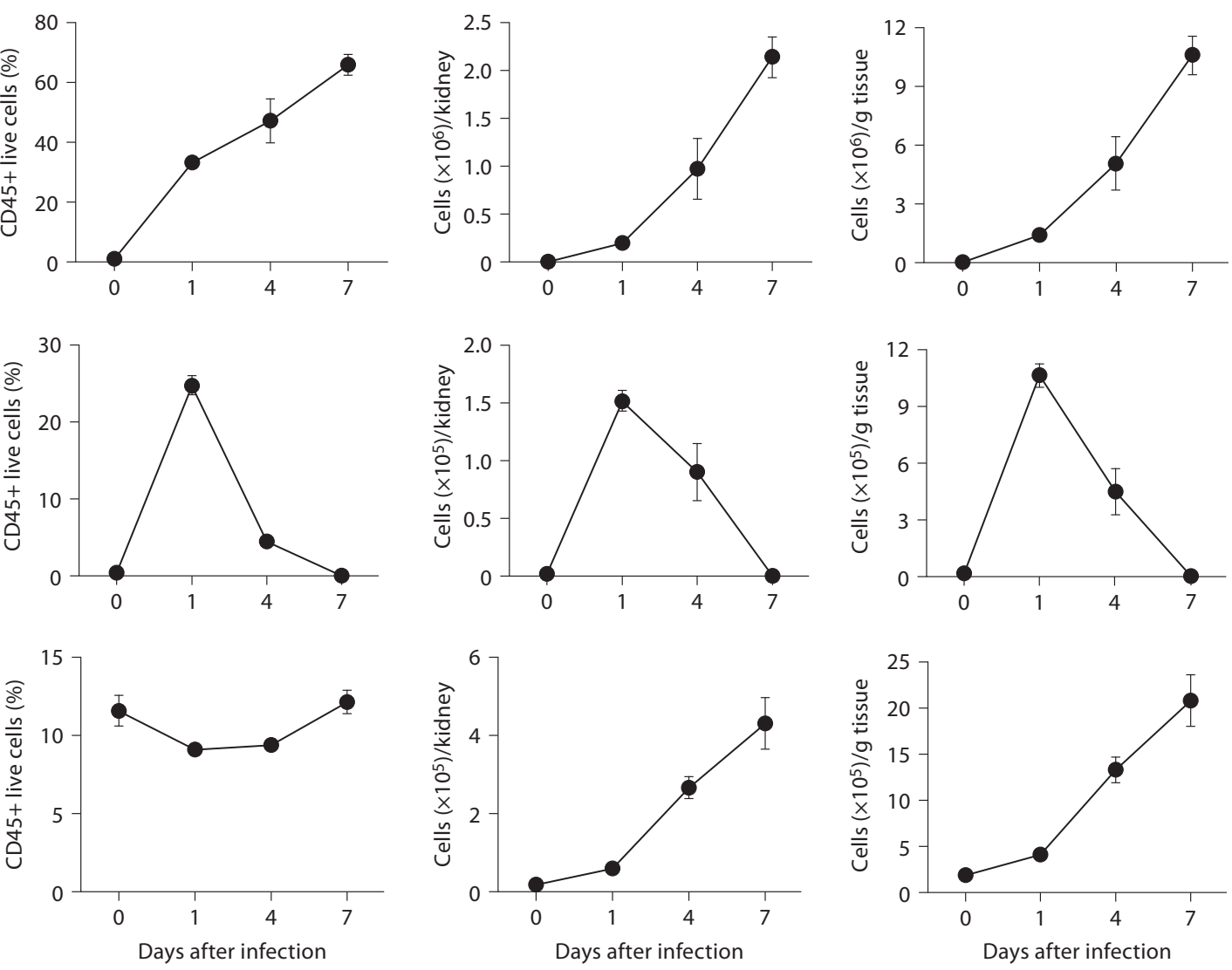

Fig. 3. Kidney-specific cellular immune response in a fatal mouse model of systemic IC. Inoculum, $2.5 \times 10^{5}$ CFU. c Representative FACS plots of neutrophils and inflammatory monocytes in the kidney at different time points after infection and in the uninfected state. Graphs show neutrophils, monocytes and macrophages as percent of $\mathrm{CD} 45^{+}$cells, and as absolute numbers per kidney or per gram of tissue. 


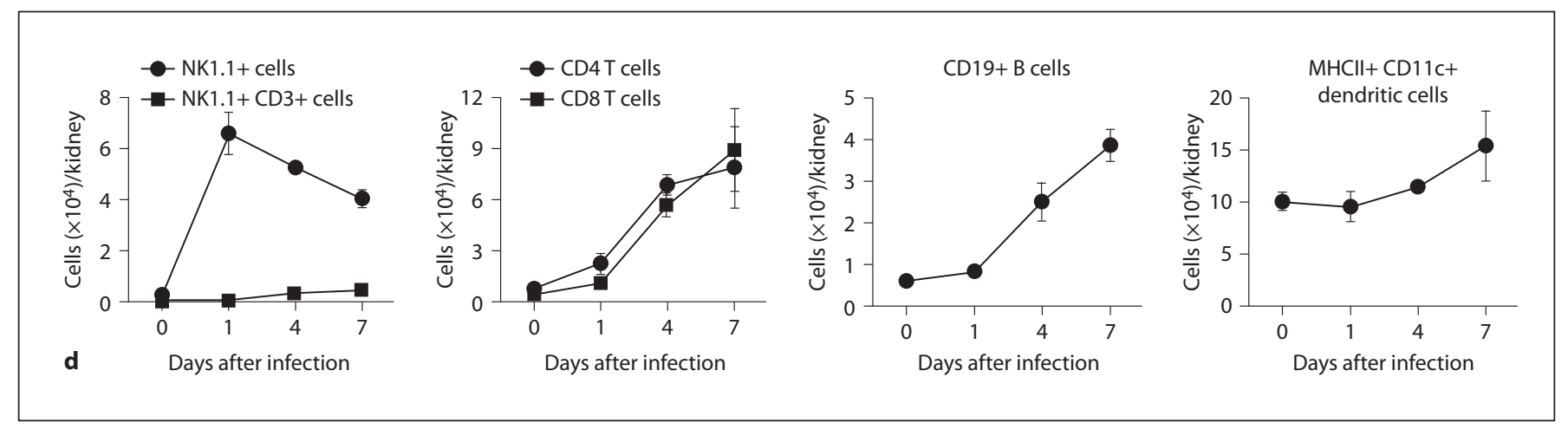

Fig. 3. Kidney-specific cellular immune response in a fatal mouse model of systemic IC. Inoculum, $2.5 \times 10^{5} \mathrm{CFU}$. d Accumulation of NK1.1 $1^{+}$cells, T and B lymphocytes, and dendritic cells in kidney after IC. Data are from a single FACS experiment with 3 mice per time point. Graphed are the mean \pm SEM data. e Representative NKp $46^{+}$IHC image from the kidney on day 4 after infection showing NK cells in the renal interstitium (arrows). Original magnification: $\times 400$.

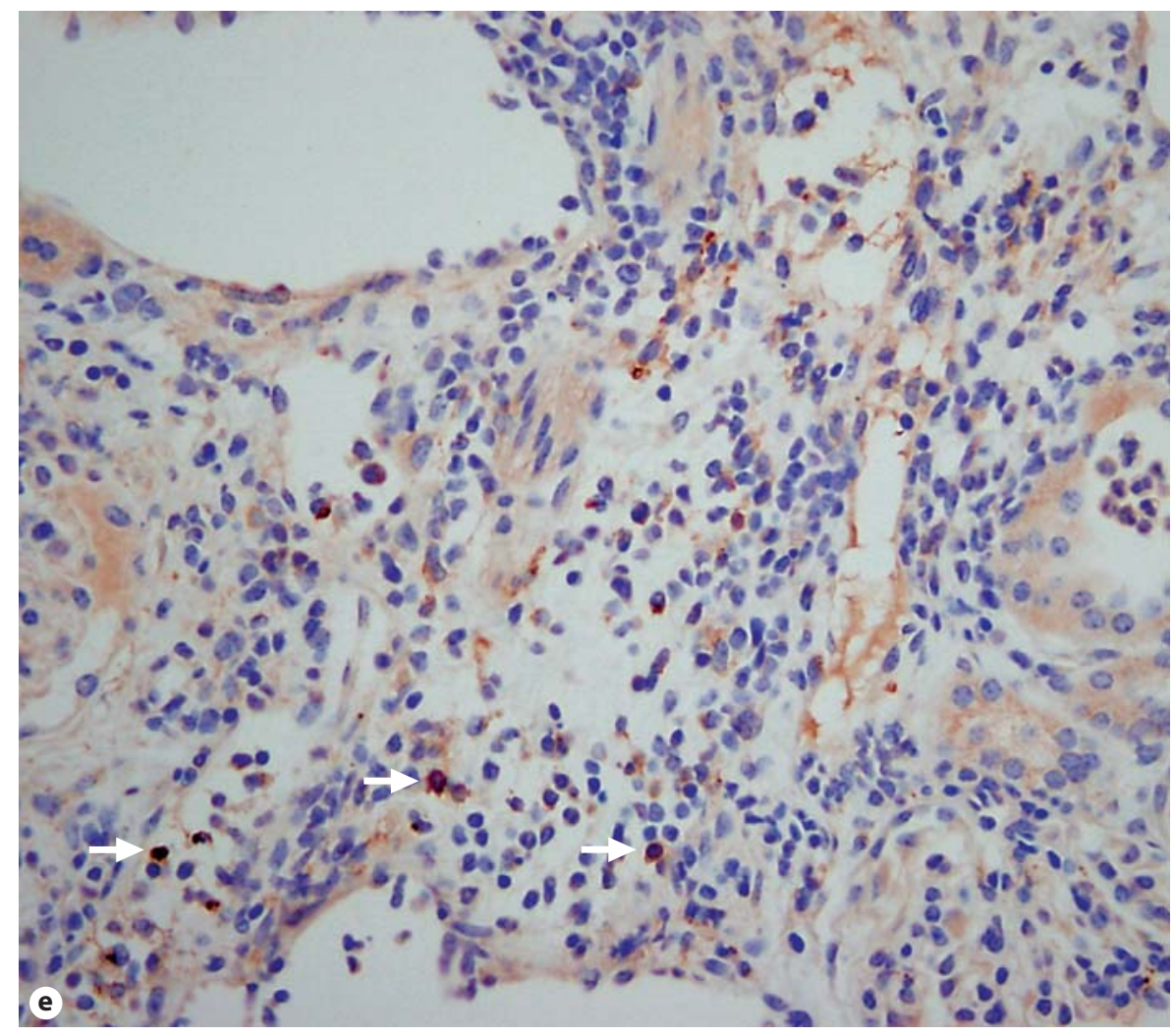

$\mathrm{MHCII}^{+} \mathrm{F} 4 / 80^{+} \mathrm{CD} 11 \mathrm{c}^{-}$macrophages increased later than monocytes after infection and were the second most abundant leukocyte subtype on days 4 and 7 after infection ( $10-15 \%$; fig. $3 \mathrm{c})$. Like monocytes, NK cells also accumulated early on day 1 after infection (fig. 3d), and were detected using NKp46 antibody by IHC throughout the infection in the renal interstitium but not within $7 / 4^{+}$ abscesses (fig. 3e). Both CD8 and CD4 T cells and B cells increased later ( $>$ day 4 after infection), whereas no expansion was seen for NKT or dendritic cells, the latter being the major leukocyte subtype found in uninfected kidney ( $\sim 50-60 \%$; fig. $3 d)$. $\gamma \delta$ T cells were not detected at any time point during the experiment. Addition of $1 \%$ BSA without 7/4 or NKp46 monoclonal antibody did not result in immunoreaction (data not shown). Thus, these data show that after an initial delay, neutrophils accumulate in large numbers organized as large abscesses in the kidney. This delay may facilitate Candida conversion to hyphae and uncontrolled Candida growth, whereas the inexorable late increase may contribute to tissue destruction and organ failure. 

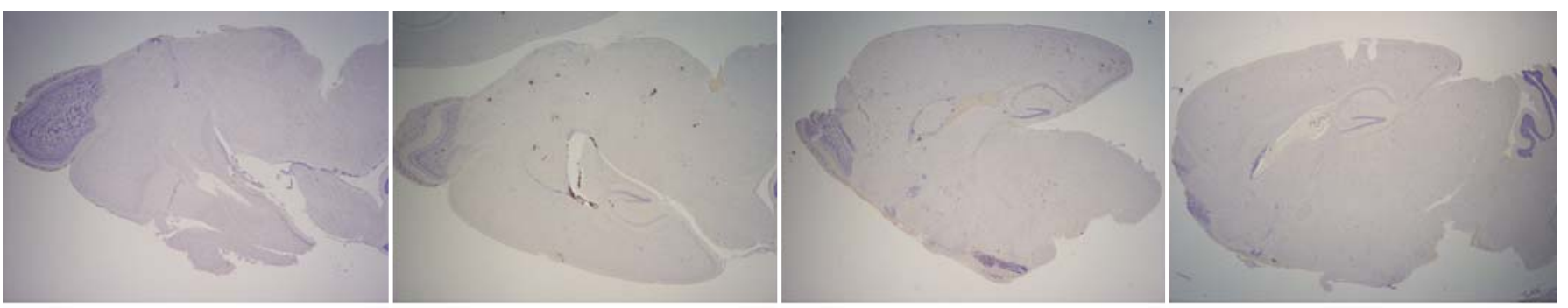

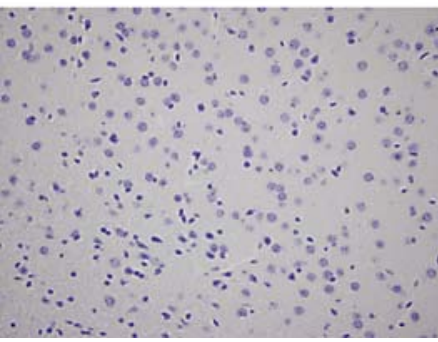

Uninfected

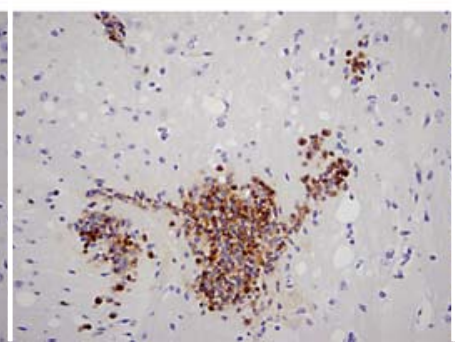

1

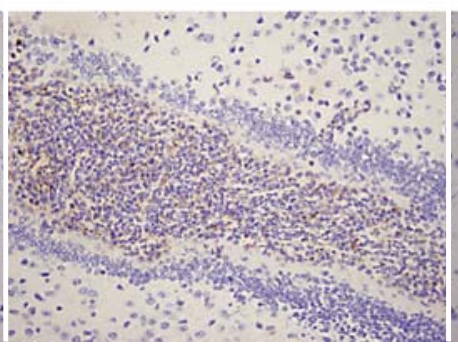

4

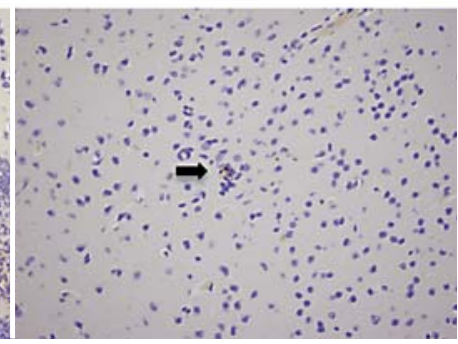

7

a

Time after infection (days)

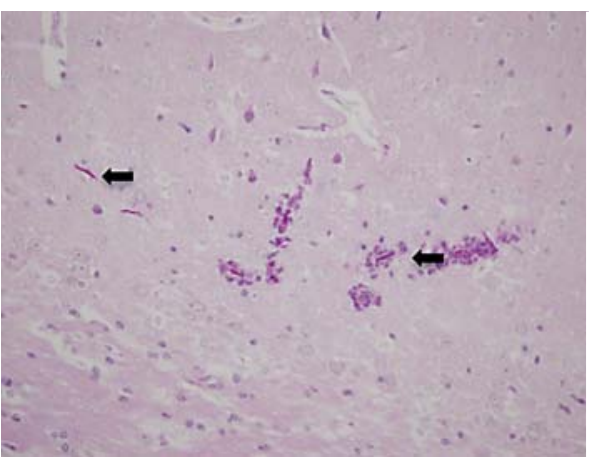

1

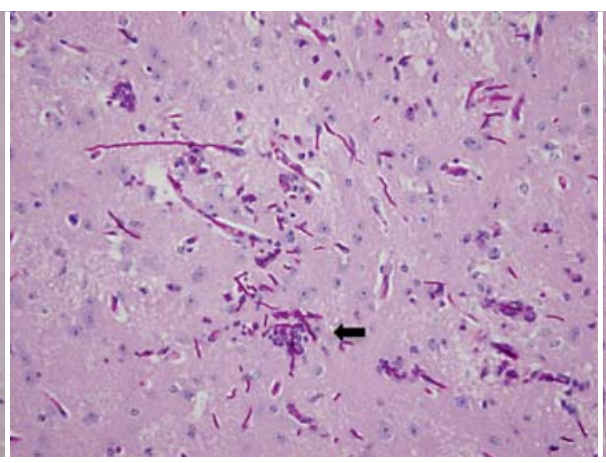

4

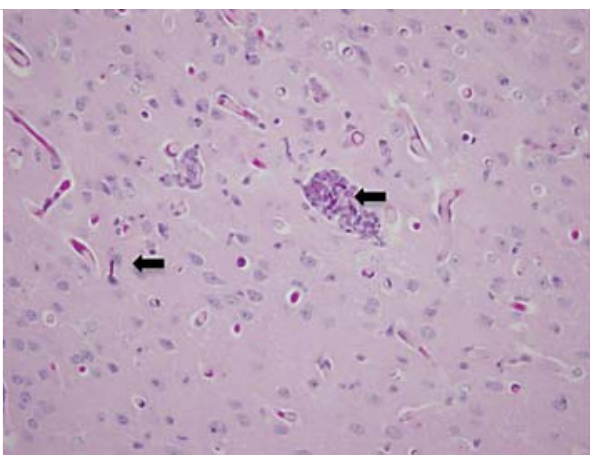

7

b

Time after infection (days)

Fig. 4. Brain-specific cellular immune response in a fatal mouse model of systemic IC. Inoculum, $2.5 \times 10^{5} \mathrm{CFU}$. a Representative $7 / 4^{+}$IHC images from brain sagittal sections at different time points after infection. Original magnifications: $\times 20$ (top row) and $\times 400$ (bottom row). Brown color represents $7 / 4^{+}$immune cells. b Representative PAS staining of the brain at different time points after infection. Original magnification: $\times 400$. Arrows point to representative Candida hyphae. c Representative FACS plots of neutrophils and inflammatory monocytes in the brain at different time points after infection and in the uninfected state. Graphs show neutrophils, monocytes and macrophages as percentages of $\mathrm{CD} 45^{+}$cells, and as absolute numbers per brain or per gram of tissue. d Accumulation of NK1.1 $1^{+}$cells, T and B lymphocytes, and dendritic cells in brain after IC.
Microglia Are the Predominant Leukocyte Population in the Brain during IC

In contrast to the kidney, the inflammatory process was neither progressive nor destructive in the brain. Specifically, $7 / 4^{+}$immunoreactivity was not detected in the brain before infection, but became evident by day 1 after infection, when phagocytes formed small scattered multifocal abscesses predominantly in the gray matter; the cerebellum was spared (fig. 4a). Unlike the kidney, there was no expansion of the inflammatory process after this time point. Moreover, the brain architecture remained intact and the number of $7 / 4^{+}$cells declined; few if any could be detected by day 7 after infection (fig. 4a). Gliosis was apparent on days 4 and 7 after infection (fig. 4a). As with the kidney, both neutrophils and mononuclear phagocytes comprised the $7 / 4^{+}$cells seen in the brain af- 

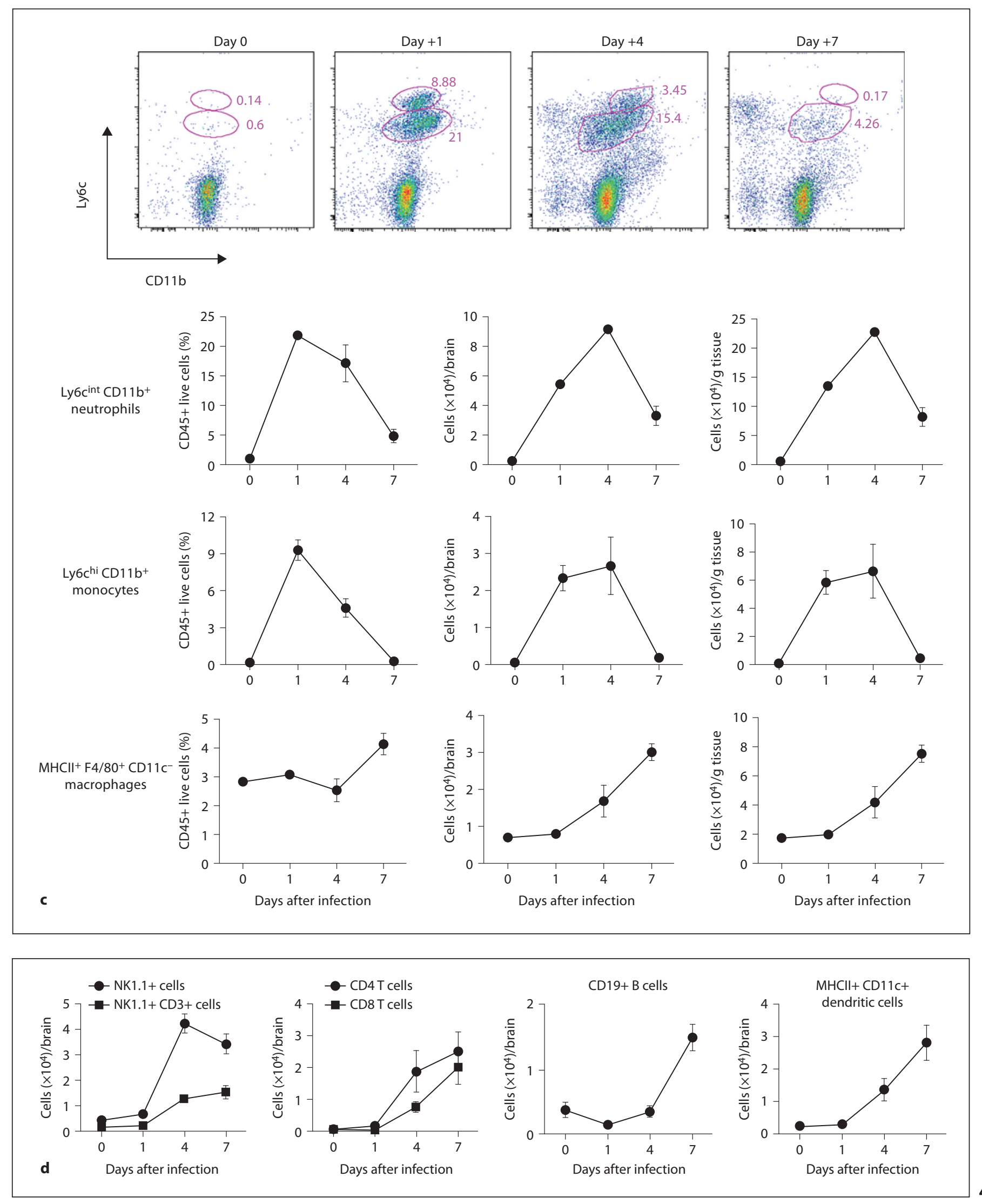


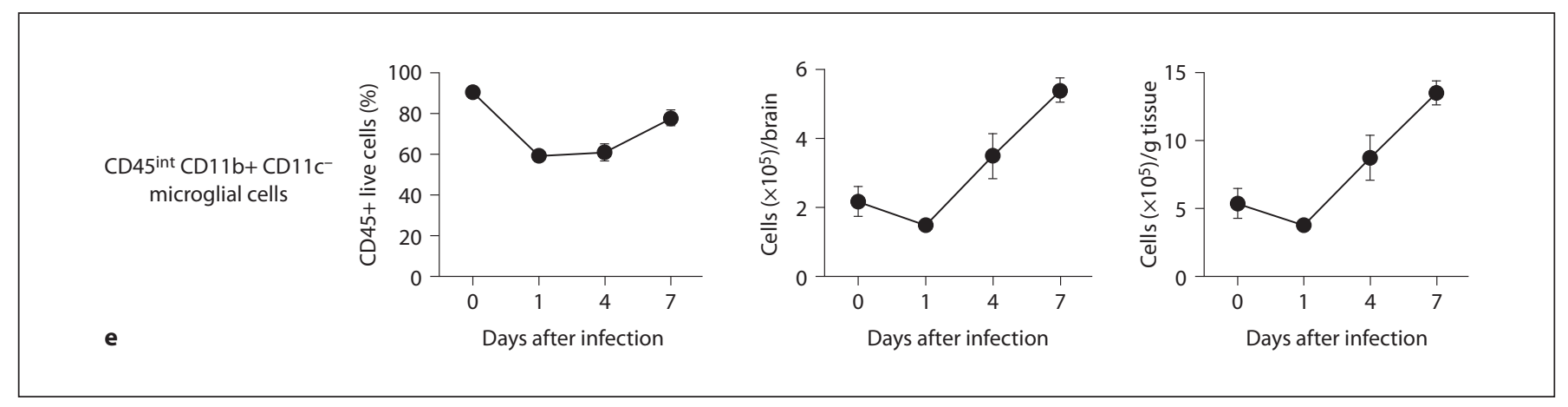

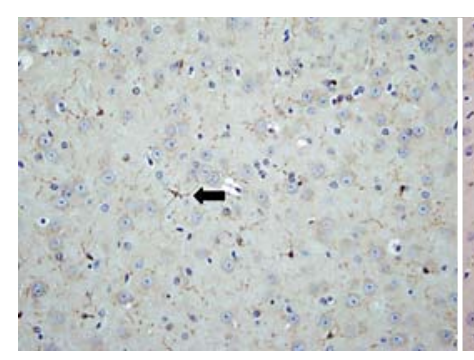

Uninfected

f

Fig. 4. Brain-specific cellular immune response in a fatal mouse model of systemic IC. Inoculum, $2.5 \times 10^{5} \mathrm{CFU}$. e Accumulation of microglia in the brain after Candida challenge. Graphs show microglial cells as percent of $\mathrm{CD} 45^{+}$cells, and as absolute numbers per brain or per gram of tissue. Data are from a single FACS

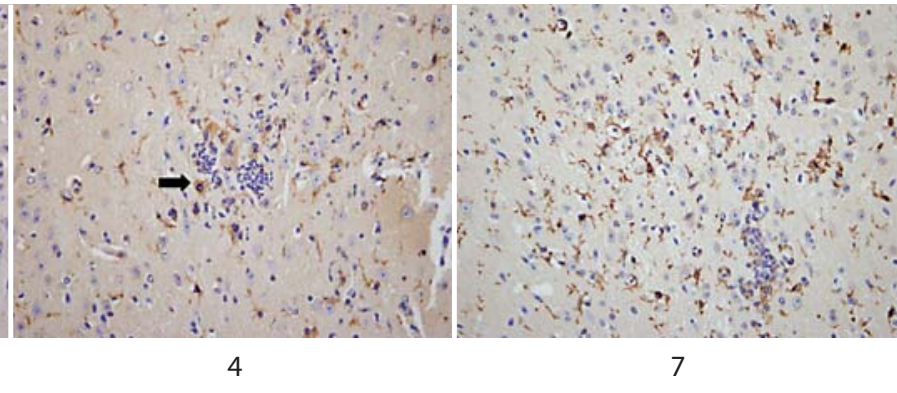

Time after infection (days)

experiment with 3 mice per time point. Graphed are the mean \pm SEM data. $\mathbf{f}$ Representative Iba1 ${ }^{+}$IHC images from the brain at different time points after infection. Original magnification: $\times 400$. Brown color represents $\mathrm{Iba}^{+}$microglia. Arrows point to representative $\mathrm{Iba}^{+}$microglia. ter infection. Conversion of Candida yeasts to hyphae was seen early on day 1 , and the number of hyphae increased through day 4 , but by day 7 , Candida growth was contained. Throughout the course of the experiment, Candida co-localized with infiltrating phagocytes (fig. 4b).

FACS analysis was used to further characterize the $7 / 4^{+}$phagocyte expansion seen in the brain. As shown in figure $4 c$, Ly $6 c^{\text {int }} \mathrm{CD} 11 b^{+}$neutrophils and Ly $6 c^{\text {hi }} \mathrm{CD} 11 b^{+}$ monocytes accumulated in the brain on days 1 (i.e. $\sim 22$ and $\sim 9 \%$ of leukocytes, respectively) and 4 (i.e. $\sim 17$ and $\sim 5 \%$ of leukocytes, respectively) but had decreased substantially by day 7 after infection (i.e. $\sim 5$ and $<1 \%$ of leukocytes, respectively). The kinetics of $\mathrm{MHCII}^{+}$ $\mathrm{F} 4 / 80^{+} \mathrm{CD} 11 \mathrm{c}^{-}$macrophage expansion was the opposite, with macrophages accumulating in the brain late after infection (fig. 4c), suggesting that monocytes may differentiate into $\mathrm{MHCII}^{+} \mathrm{F} 4 / 80^{+} \mathrm{CD} 11 \mathrm{c}^{-}$macrophages during the course of IC. NK and NKT cells, T and B lymphocytes, and dendritic cells all accumulated in the brain af- ter infection, but with differential dynamics (fig. 4d), whereas $\gamma \delta$ T cells were not detected. Of note, NK cells $\left(\mathrm{NK} 1.1^{+}, \mathrm{CD}^{-}\right)$were the third most abundant leukocyte subtype in the brain on day 4 after infection $(\sim 5-9 \%$; fig. $4 \mathrm{~d})$. However, the cell type that populated the brain to the greatest extent after infection was by far $\mathrm{CD} 45^{\text {int }} \mathrm{CD} 11 \mathrm{~b}^{+} \mathrm{CD} 11 \mathrm{c}^{-}$microglia, which increased 3-fold by day 7 , thus outnumbering neutrophils $\sim 7$-fold (fig. 4 e). The microglial expansion after infection was verified using IHC with Iba1, a microglia-specific marker (fig. 4f) [13]. Of interest, microglia co-localized with neutrophils at sites of Candida invasion and tended to surround neutrophilic abscesses (fig. 4g). In contrast, no microglial expansion was observed in areas where neither Candida nor neutrophils were present (fig. 4h). Addition of $1 \%$ BSA without $7 / 4$ or Iba1 monoclonal antibody did not result in immunoreaction (data not shown). Thus, our results show significant microglial expansion in the brain after infection, associated with transient neutrophil accumulation and Candida control. 

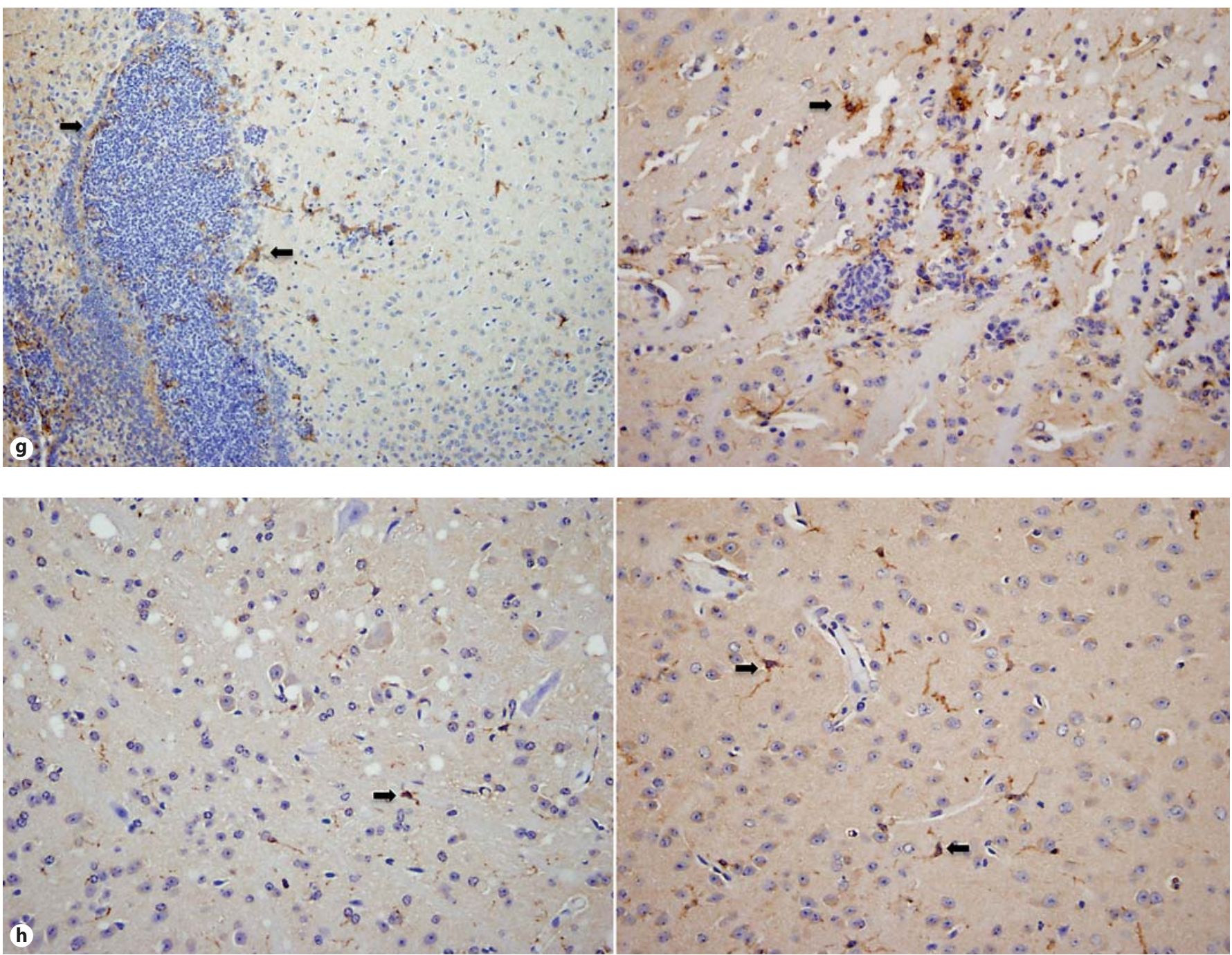

Fig. 4. Brain-specific cellular immune response in a fatal mouse model of systemic IC. Inoculum, $2.5 \times 10^{5}$ CFU. g Iba1 ${ }^{+}$IHC brain images on day 4 after infection showing accumulation of microglia (arrows) around neutrophilic abscesses. Original mag-

nification: $\times 400$. $\mathbf{h ~} \mathrm{Iba1}^{+}$IHC brain images on day 4 after infection showing no expansion of microglia in brain areas where neutrophils are not present. Arrows point to representative $\mathrm{Iba}^{+} \mathrm{mi}-$ croglia. Original magnification: $\times 400$.

The Spleen Accumulates the Most Phagocytes of All Organs and Prevents Candida Filamentation

$7 / 4^{+}$cells were constitutively present in uninfected spleen throughout the red pulp but increased substantially during IC (fig. 5a). These cells were identified only in the red pulp without infiltration of the white pulp of the spleen at any time point following infection. As seen in the kidney and brain, both neutrophils and mononuclear phagocytes comprised the $7 / 4^{+}$cells infiltrating the spleen after infection. Nonetheless, unlike the kidney and brain, there was no abscess formation in the spleen, and the splenic architecture was preserved with prominent hemosiderin deposition on day 1 and splenomegaly as the infection progressed (fig. 5a). Addition of $1 \%$ BSA without $7 / 4$ monoclonal antibody did not result in immunoreaction (data not shown). Of note, Candida filamentation was not observed at any time point after infection. Instead, only Candida yeasts were found, on days 1 and 4, engulfed and/ or surrounded by phagocytes (fig. 5b). On day 7 after infection, no Candida was detected by PAS or Gomori-Grocott methenamine silver stain (data not shown). 

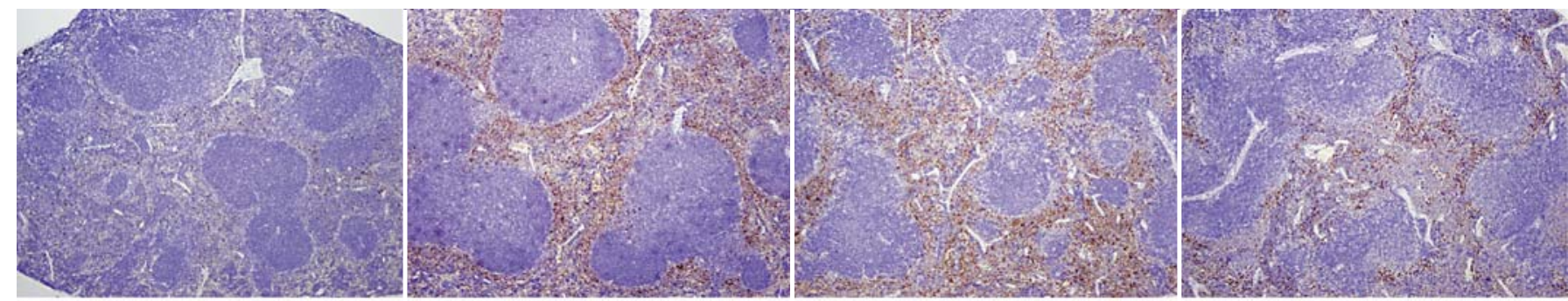

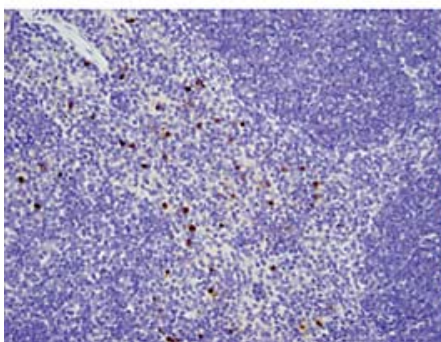

Uninfected

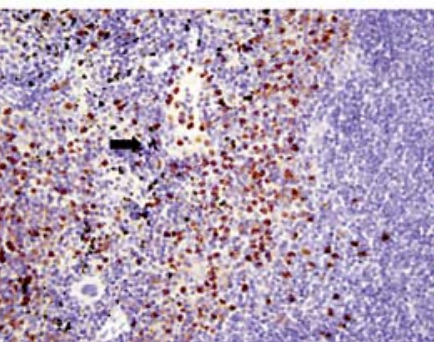

1

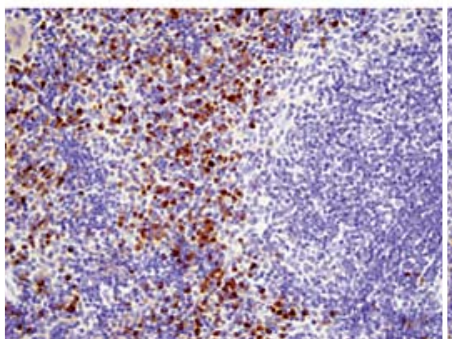

4

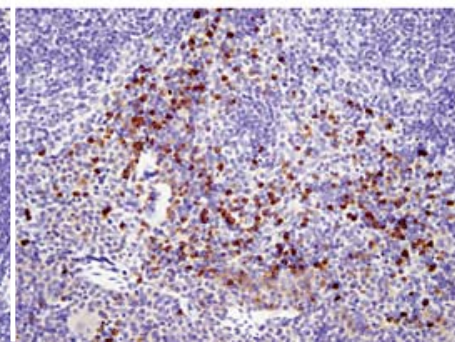

7

a

Time after infection (days)

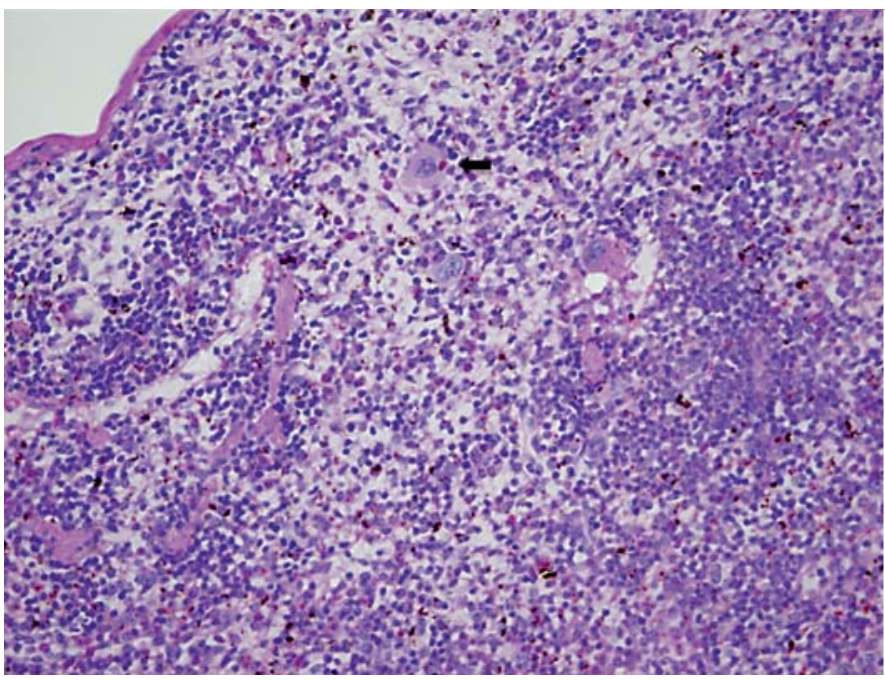

1

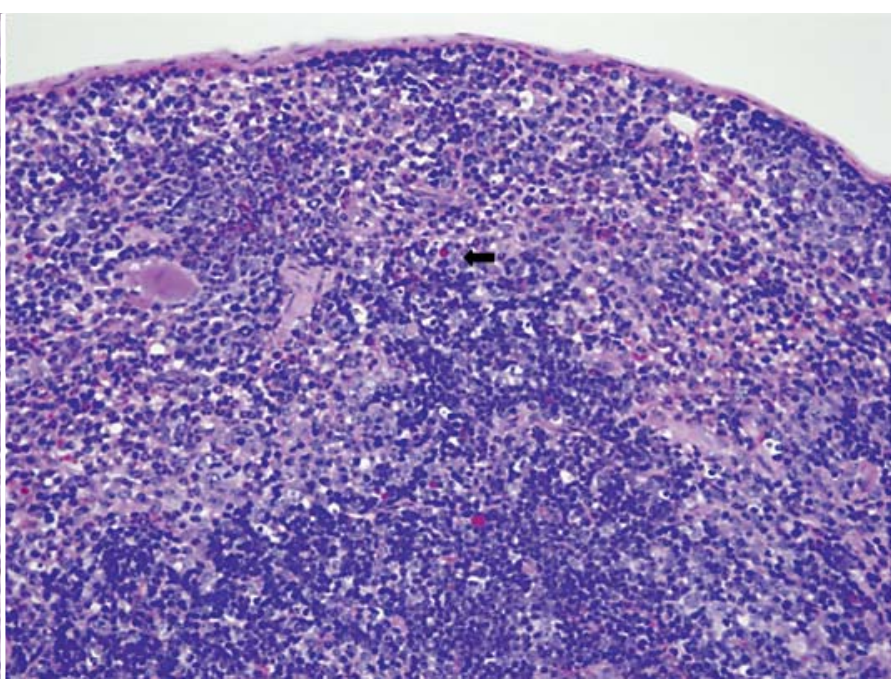

4

b

Time after infection (days)

Fig. 5. Spleen-specific cellular immune response in a fatal mouse model of systemic IC. Inoculum, $2.5 \times 10^{5} \mathrm{CFU}$. a Representative $7 / 4^{+}$IHC images from spleen cross-sections at different time points after infection. Original magnifications: $\times 20$ (top row) and $\times 400$ (bottom row). Brown color represents $7 / 4^{+}$immune cells and the arrow points to hemosiderin deposition. b Representative PAS staining of the spleen at different time points after infection. Original magnification: $\times 400$. Arrows point to Candida yeasts. $\mathbf{c}$ Rep- resentative FACS plots of neutrophils and inflammatory monocytes in the spleen at different time points after infection and in the uninfected state. Graphs show neutrophils, monocytes and macrophages as percent of $\mathrm{CD} 45^{+}$cells, and as absolute numbers per spleen or per gram of tissue. d Accumulation of NK1.1+ cells, $\mathrm{T}$ and $\mathrm{B}$ lymphocytes, and dendritic cells in the spleen after Candida challenge. Data are from a single FACS experiment with 3 mice per time point. Graphed are the mean \pm SEM data. 

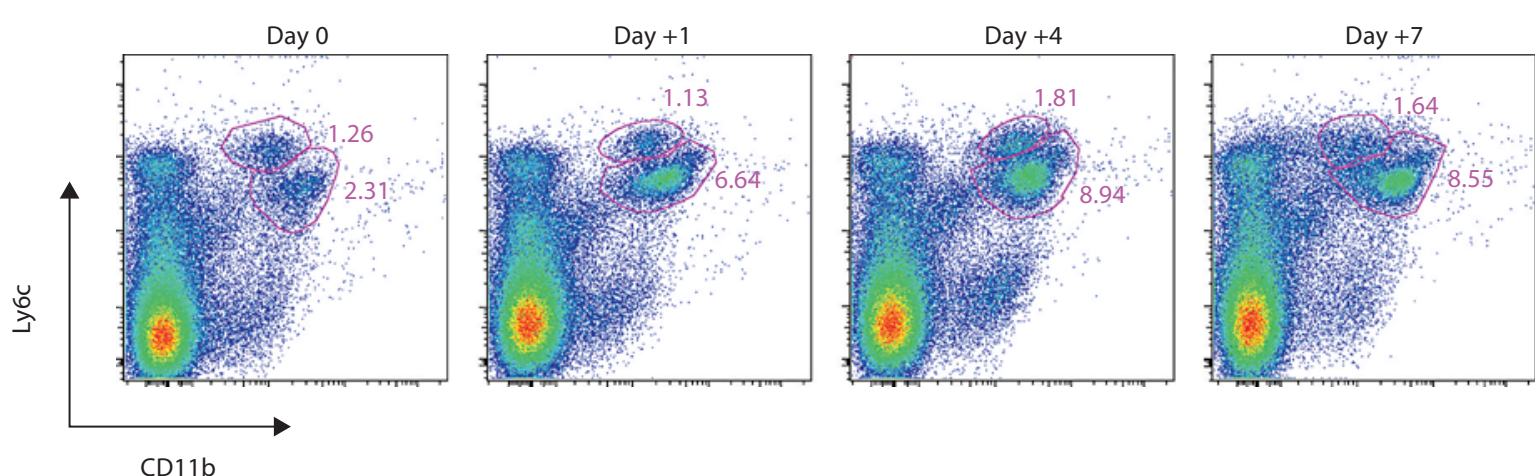

CD11b
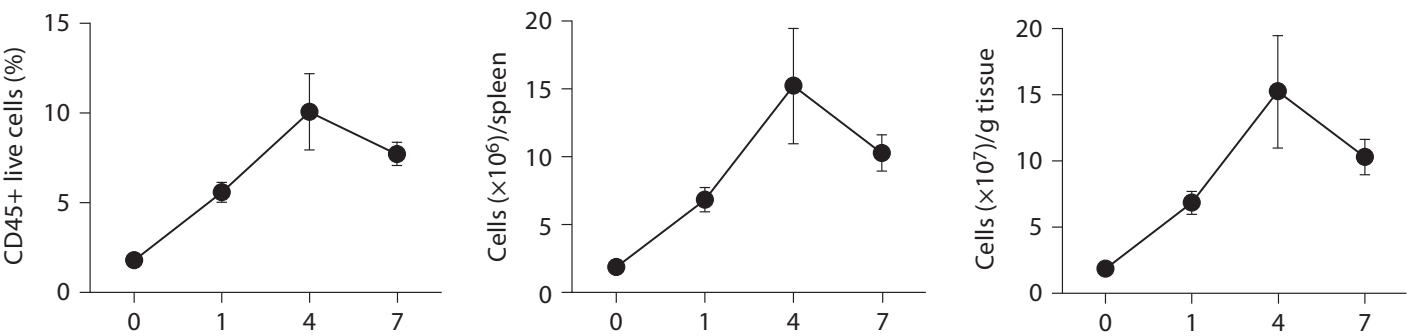

monocytes
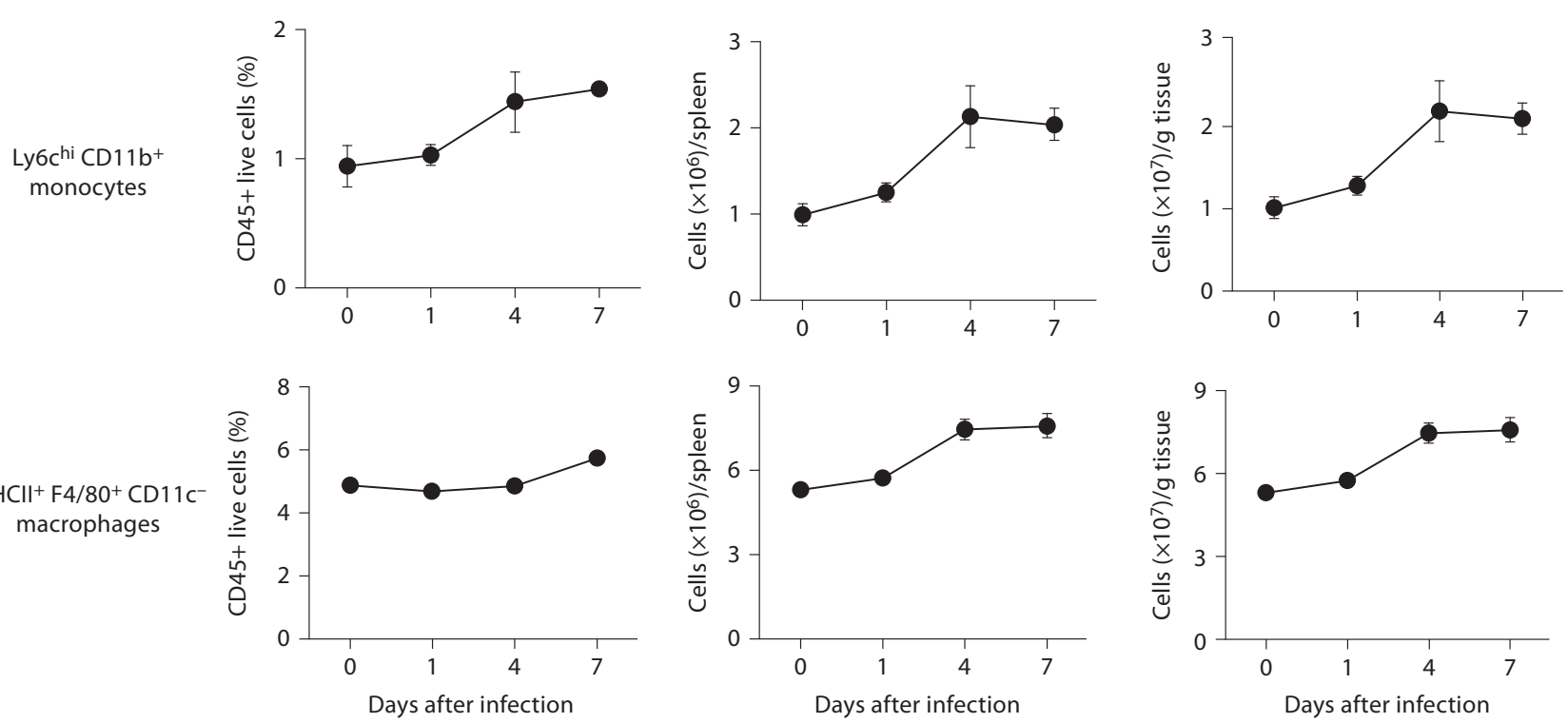

Days after infection

C
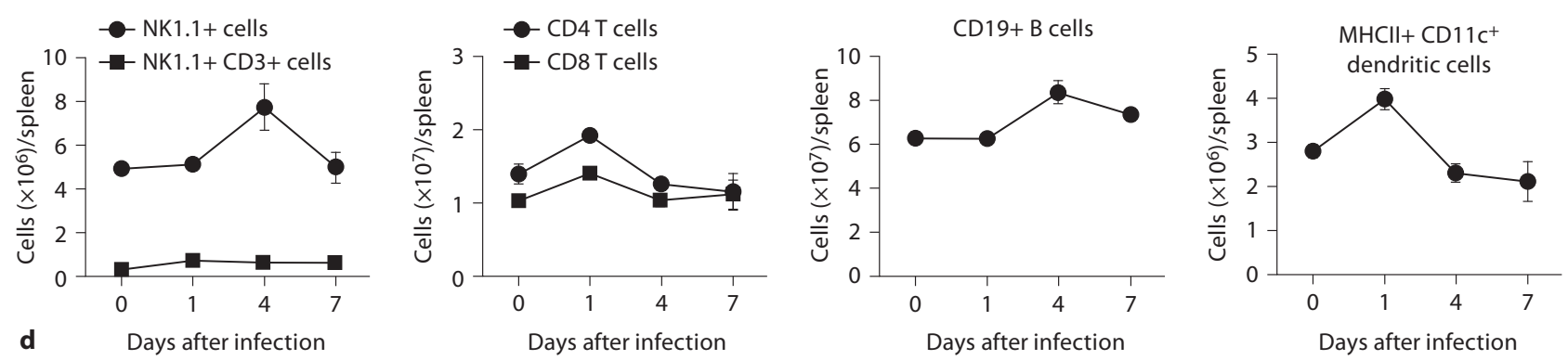

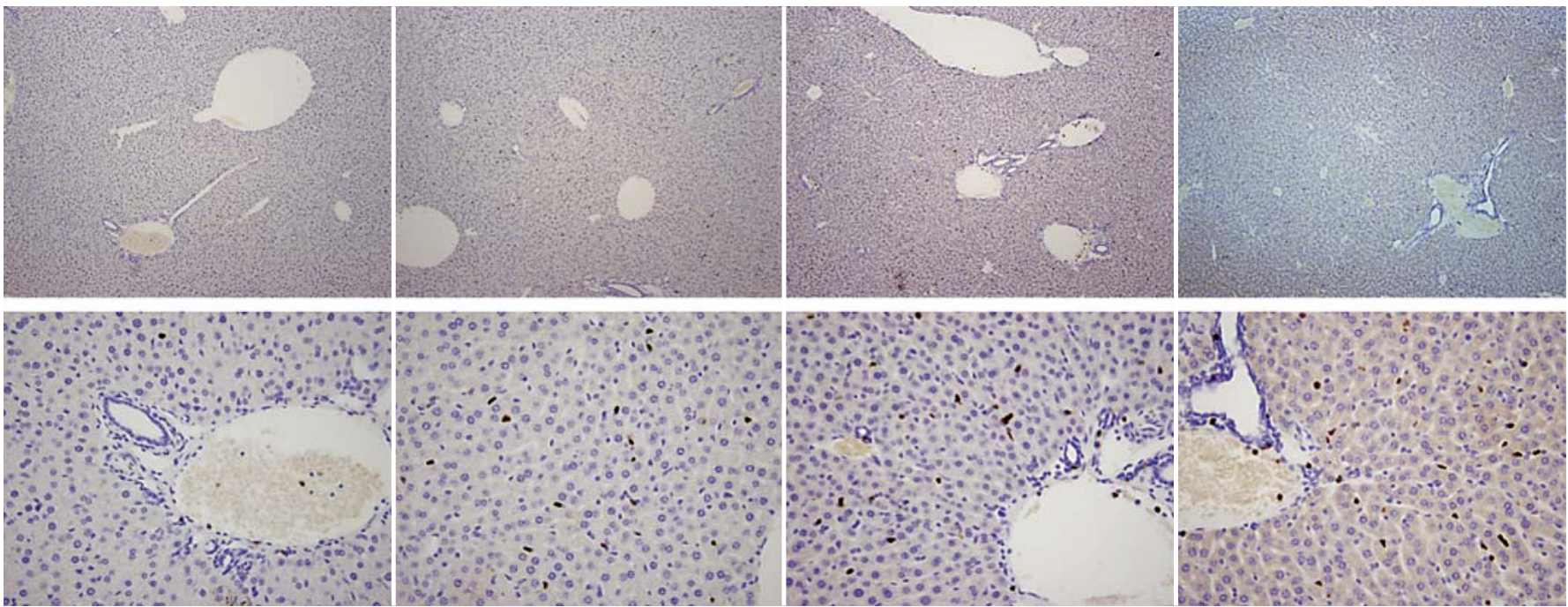

Uninfected

1

7

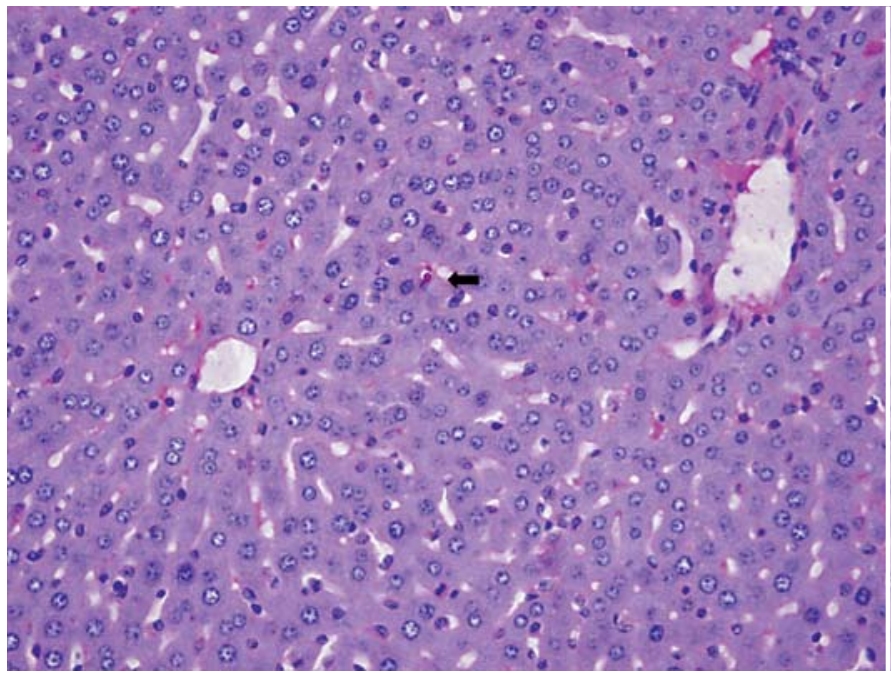

Time after infection (days)

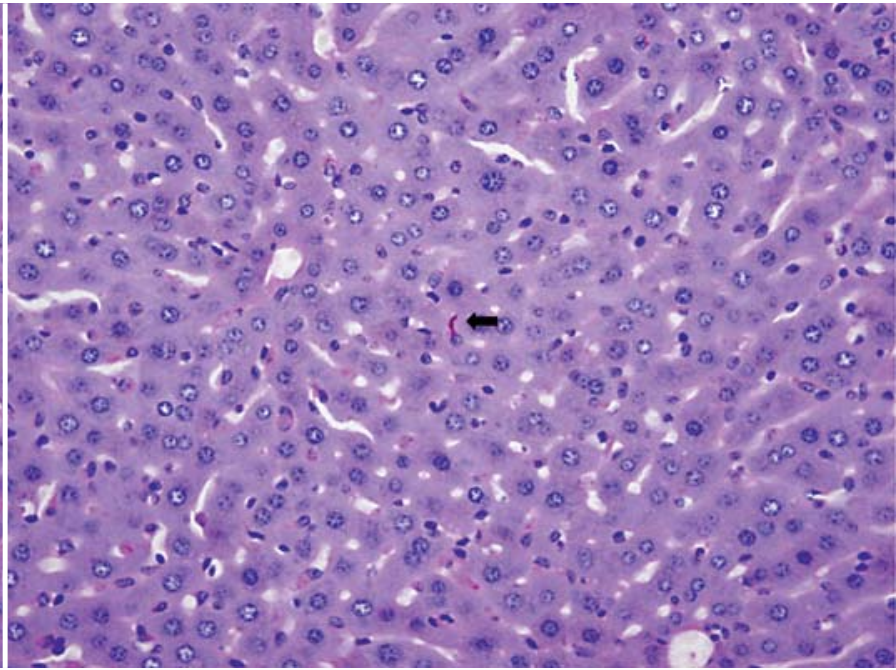

Time after infection (days)

Fig. 6. Liver-specific cellular immune response in a fatal mouse model of systemic IC. Inoculum, $2.5 \times 10^{5} \mathrm{CFU}$. a Representative $7 / 4^{+}$IHC images from liver cross-sections at different time points after infection. Original magnifications: $\times 20$ (top row) and $\times 400$ (bottom row). Brown color represents $7 / 4^{+}$immune cells. b Representative PAS staining of the liver at different time points after infection. Original magnification: $\times 400$. Arrows point to Candida yeast and germ tube forms. c Representative FACS plots of neutrophils and inflammatory monocytes in the liver at different time points after infection and in the uninfected state. Graphs show neutrophils, monocytes and macrophages as percent of $\mathrm{CD} 45^{+}$cells, and as absolute numbers per liver or per gram of tissue. d Accumulation of NK1.1 $1^{+}$cells, T and B lymphocytes, and dendritic cells in the liver after Candida challenge. Data are from a single FACS experiment with 3 mice per time point. Graphed are the mean \pm SEM data. 

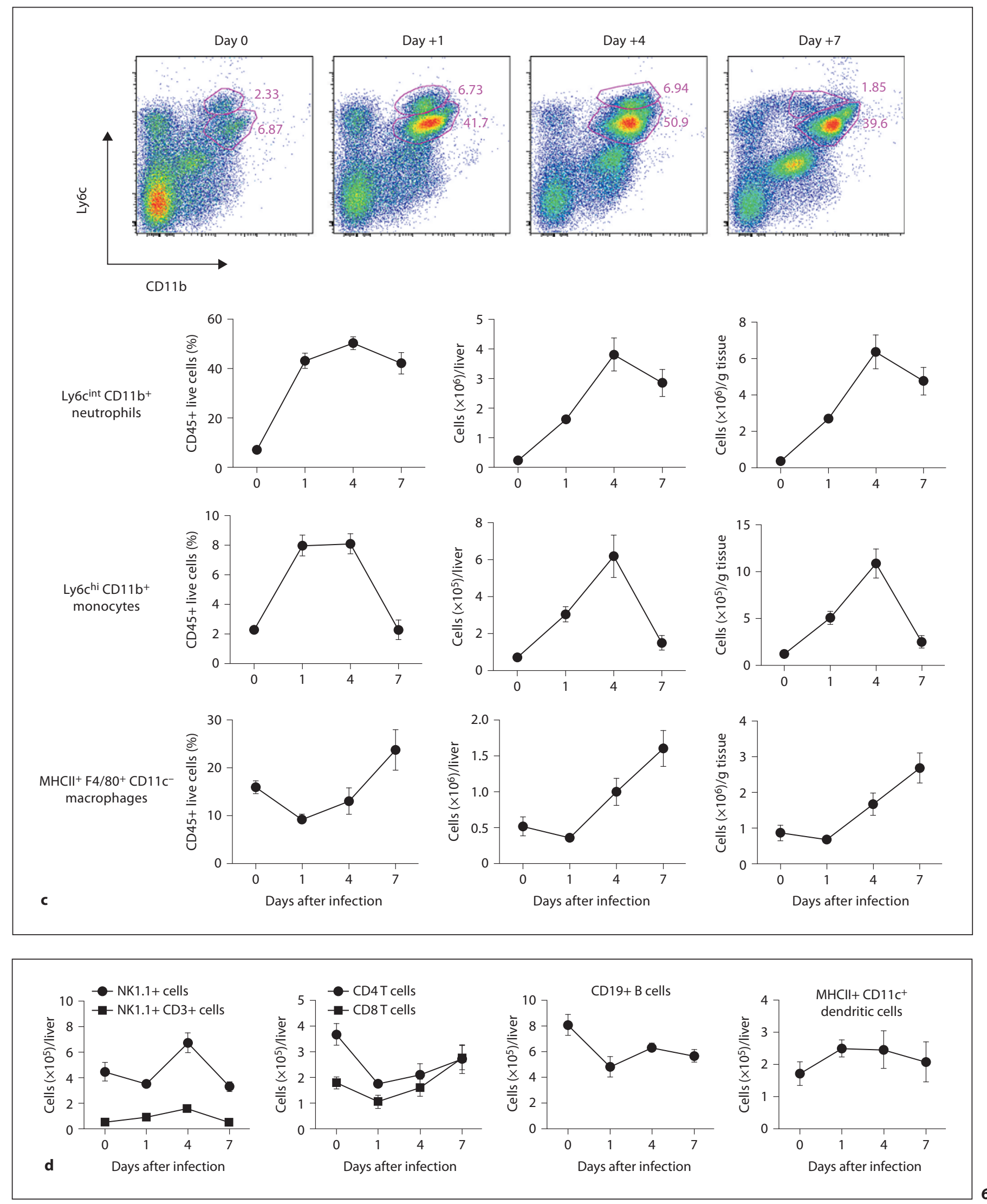
Using FACS analysis, we verified the significant $7 / 4^{+}$ cell accumulation in the spleen during IC. Approximately $2 \times 10^{6} \mathrm{Ly}_{6} \mathrm{c}^{\text {int }} \mathrm{CD} 11 \mathrm{~b}^{+}$neutrophils were detected in uninfected spleen, and following infection, they accumulated further reaching $\sim 1.5 \times 10^{8}$ cells/g tissue on day 4 $\left(\sim 10 \%\right.$ of $\mathrm{CD} 45^{+}$cells), and then decreased by day $7(\sim 7-$ $8 \%$ of $\mathrm{CD} 45^{+}$cells; fig. $5 \mathrm{c}$ ). Similarly, Ly6chi $\mathrm{CD} 11 \mathrm{~b}^{+}$ monocytes and $\mathrm{MHCII}^{+} \mathrm{F} 4 / 80^{+} \mathrm{CD} 11 \mathrm{c}^{-}$macrophages were present in large numbers in uninfected spleen $(\sim 1$ and $5 \times 10^{6}$ cells, respectively) and increased $\sim 1.5$ - to 2 -fold after infection, comprising $\sim 1$ to $2 \%$ and $5-6 \%$ of $\mathrm{CD}^{2} 5^{+}$cells (fig. 5 c). NK and B cells also accumulated after infection, whereas NKT and $\gamma \delta$ T cells, T lymphocytes and dendritic cells did not (fig. 5d, and data not shown). Hence, our results show that phagocytes, which are already present in large numbers in the uninfected spleen, accumulated to the greatest extent in this organ compared to all organs examined during IC. In addition, Candida filamentation, an essential virulence trait [17], was not observed in the spleen after infection.

In the Liver Phagocytes Accumulate in Large Numbers but Do Not Organize into Abscesses, nor Does

Candida Form Hyphae during IC

Scattered $7 / 4^{+}$cells were detected in uninfected liver (fig. 6a). Following infection, there was an accumulation of both $7 / 4^{+}$neutrophils and mononuclear phagocytes throughout the entire liver parenchyma, but no abscesses formed and tissue architecture was preserved without evident inflammatory changes or granuloma formation (fig. 6a). Addition of 1\% BSA without 7/4 monoclonal antibody did not result in immunoreaction (data not shown). Candida filamentation was not observed at any time point after infection. Only Candida yeasts and germ tubes were found on days 1 and 4 after infection (fig. 6b), whereas no fungal elements were detected on day 7 by PAS or Gomori-Grocott methenamine silver stain (data not shown).

Using FACS, $\sim 250,000$ Ly $6 \mathrm{c}^{\mathrm{int}} \mathrm{CD} 11 \mathrm{~b}^{+}$neutrophils were found in the uninfected liver, comprising $\sim 7$ to $8 \%$ of $\mathrm{CD}_{4} 5^{+}$cells. During IC, neutrophils accumulated further with an early $\sim 10$-fold increase over baseline by day $1(\sim 40-45 \%)$, an $\sim 20$-fold increase by day 4 peaking at $\sim 6 \times 10^{6}$ cells/g tissue ( $\left.\sim 50 \%\right)$, and a subsequent decrease by day 7 after infection ( $40-45 \%$; fig. $6 c)$. Ly $6 \mathrm{c}^{\text {hi }} \mathrm{CD} 11 \mathrm{~b}^{+}$monocytes also peaked on day $4(\sim 600,000$ or $7-9 \%$ of $\mathrm{CD} 45^{+}$cells), increasing from $\sim 70,000$ $(\sim 2 \%)$ at steady-state conditions, and returned to uninfected-state levels on day 7 following infection. $\mathrm{MHCII}^{+} \mathrm{F} 4 / 80^{+} \mathrm{CD} 11 \mathrm{c}^{-}$macrophages were present in un- infected liver at $\sim 1 \times 10^{6}$ cells $/ g$ tissue and expanded $\sim 3$-fold by day 7 comprising $\sim 25 \%$ of liver leukocytes (fig. 6c). NK and NKT cells and CD8 T lymphocytes also accumulated, while $\gamma \delta \mathrm{T}$ cell, CD4 T lymphocyte, B lymphocyte and dendritic cell numbers did not significantly increase (fig. $6 \mathrm{~d}$, and data not shown). These data show that the liver accumulates large numbers of phagocytes early after infection and, as in the spleen, Candida filamentation is impaired.

\section{Discussion}

We present - to our knowledge - the first detailed analysis of leukocyte subset accumulation in different Candida-infected tissues. We have shown in a mouse model of disseminated IC that the innate immune system responds in an organ-specific temporal and spatial manner, and varies markedly among organs in its ability to control the organism. This model is particularly well suited for investigating fundamental questions regarding organ-specific immunity, since Candida disseminates from the bloodstream to all organs and grows as an extracellular pathogen, in the yeast and/or hyphal morphogenic states [18].

When Candida is introduced into the bloodstream, $>99 \%$ is cleared within the $1 \mathrm{st} \mathrm{h}$, and no organisms can be isolated from the blood 7 days after infection, paradoxically at a time when the animals are dying of overwhelming destructive Candida infection in the kidney. In contrast, the brain, spleen, and liver eventually control Candida without developing infection-related immunopathology. Herein, we show that neutrophils are the principal leukocytes infiltrating Candida-infected tissues except the brain. Neutrophils are reported to be dispensable for effective anti-Candida host defense in the brain $[5,6]$. Consistent with this, the brain accumulates neutrophils the least compared to all other organs, and yet Candida is controlled. Conversely, the predominant $\mathrm{CD} 45^{+}$cells accumulating at sites of brain invasion by Candida are microglia. Microglia can phagocytose and kill Candida, and when administered locally as prophylaxis before intracerebral Candida inoculation, they protect against lethal challenge and ameliorate infection-associated tissue damage [19]. Likewise, our study shows that, in bloodstream-derived brain infection by Candida, microglia appear to be key innate immune effector cells for Candida control, and possibly for preventing neutrophil-induced immunopathology. Because microglia expand locally both by in situ proliferation and recruitment from 
blood monocytes [20], the relative contribution of CX3CR $1{ }^{\text {hi } C C R} 2^{-}$resident versus CX $3 C R 1^{\text {int }} \mathrm{CCR} 2{ }^{\text {hi }}$ inflammatory monocyte-derived microglia in anti-Candi$d a$ brain host defense should be explored.

Contrary to the brain, neutrophils are essential for Candida control in the kidney, spleen, and liver [6]. Although neutrophils expand in all three organs, the infection progresses in the kidney but is controlled in the spleen and liver for reasons that have yet to be elucidated. Quantitative differences in early neutrophil accumulation between the kidney versus spleen and liver may provide insight into why this organ-specific difference in Candida control is observed. Hence, both before infection and on day 1 after infection, the spleen and liver accumulate significantly more neutrophils than does the kidney. This kidney-specific delay in early neutrophil availability may be significant because the timing of neutrophil presence is crucial for Candida control as illustrated by the fact that rendering mice neutropenic within the first $24 \mathrm{~h}$ after infection (but not later) leads to enhanced Candida growth and accelerated mortality [6]. Our data show that during this critical first 24-hour period, the kidney is undefended, being in a 'relatively neutropenic' state compared to the spleen and liver. In agreement, over this 24 -hour period fungal burden increases $\sim 10$-fold in the kidney, but is contained in the spleen and liver (fig. 1b). The significance of early control of Candida fungal burden is further shown by mouse and human studies, in which prompt initiation of antifungal therapy is fundamental for favorable outcome of IC $[4,21]$.

Different Candida morphogenic states between kidney versus spleen and liver may also explain the kidneyspecific inability to control Candida. Although both Candida yeast and hyphal forms are found in the kidney during IC (as reported previously $[2,5,6])$, hyphae are not detected in the spleen or liver. As Candida strains unable to form hyphae are avirulent [17] and do not elicit robust inflammatory responses [22], hyphal growth in the kidney (but not in spleen or liver) may impede kidney-specific effective immune responses because hyphae (1) are more resistant than yeasts to killing by phagocytes [23], and (2) are too large to be ingested by neutrophils, which instead degranulate and release oxidative contents extracellularly [24]. The latter may account, at least in part, for the destructive inflammatory process seen in the kidney [25]. The inability to clear Candida and the ensuing immunopathology may be stimuli for continuous neutrophil expansion in the kidney, the sole organ with persistent neutrophil accumulation on day 7, a time

Organ-Specific Innate Immune

Responses in Invasive Candidiasis point when neutrophils are detrimental for the host and neutrophil depletion improves survival [6]. Failure to clear Candida in the kidney may also relate to other organ-specific factors that (1) impair neutrophil function, such as the high osmolarity and urea content of renal tubules [26], and/or (2) enhance Candida fitness to cause invasion [27].

Neutrophil heterogeneity has been described in humans and mice $[28,29]$. In Staphylococcus aureus-infected mice, neutrophils that secrete Th1-related cytokines/ chemokines [interleukin (IL)-12, CCL3] and induce classical macrophage activation were recovered from resistant hosts, whereas neutrophils that secrete Th2-associated cytokines/chemokines (IL-10, CCL2) and induce alternatively activated macrophages were found in susceptible hosts [29]. Similar neutrophil subsets have been identified in mice infected with avirulent and virulent Candida, respectively [6, 30]. Specifically, neutrophils recovered from mice infected with the avirulent agerminative PCA-2 strain produced IL-12, whereas neutrophils recovered from mice infected with the virulent CA-6 strain produced IL-10 [30]. Likewise, neutrophils produce IL-12 in response to Candida yeasts, versus IL-10 in response to Candida hyphae in vitro [31]. Because different Candida forms were detected in the kidney versus spleen or liver, it is possible that neutrophils with differing cytokine-secreting potential, differing capacity for inducing alternative versus classical macrophage activation and differing direct candidacidal activity may infiltrate the kidney versus spleen or liver during IC. In fact, organ-specific heterogeneity in macrophage candidacidal mechanisms has been reported in vitro [32].

Our results also show that IC induces monocytosis and that $\mathrm{Ly} 6 \mathrm{c}^{\mathrm{hi}} \mathrm{CD} 11 \mathrm{~b}^{+}$inflammatory monocytes expand in all organs, and are detected in tissues using 7/4 IHC. Upon entry in infected tissue, inflammatory monocytes differentiate into macrophages and dendritic cells [33], both of which accumulate in IC in an organ-specific manner. Monocytes phagocytose and kill Candida yeasts in vitro [10] and have been shown to play both protective and pathogenic roles in various infectious models in vivo $[33,34]$. Hence, their role in organ-specific anti-Candida host defense and immunopathology, and their tissuespecific relative differentiation into macrophages and dendritic cells requires further research. Moreover, NK cells, which are constitutively present in large numbers in the spleen and liver, expand in the blood and visceral organs during IC, where they are detected using NKp46 IHC. NK cell depletion impairs interferon- $\gamma$ production in the spleen after IC [35] and inhibits anti-Candida 
phagocytic capacity of splenic macrophages in vitro [36], but whether NK cells modulate anti-Candida host defense in other tissues is unknown. Also, the role of dendritic cells in organ-specific anti-Candida immunity merits investigation, especially in light of the ability of dendritic cells to discriminate between Candida yeasts and hyphae, and to induce Th1 versus Th2 priming, respectively [37]. Finally, although adaptive immunity is dispensable for host defense in this model [9], we show here that $\mathrm{B}, \mathrm{T}$ and NKT cells accumulate during IC in an organ-specific manner and with differential dynamics. At present, the functional significance of this finding is unknown but merits further investigation.

Our study has limitations. Because this mouse model of IC has an acute tempo of progression and high infecting Candida load, it may not mimic all aspects of the pathogenesis of bloodstream-derived IC in humans, which typically is caused by inoculation of a smaller infecting yeast load and follows a more subacute course. Hence, future studies should aim at characterizing organ-specific innate immune responses in mice infected with lower sublethal Candida inocula. Furthermore, our study only examined the organ-specific innate immune responses in C57Bl/6 Candida-infected mice. Because various inbred mouse strains are known to have differential Candida susceptibility, future research should focus on comparing organ-specific innate immune responses between $\mathrm{C} 57 \mathrm{Bl} / 6$ and other strains (e.g. Balb/c and DBA). Nonetheless, our analysis of organ-specific cellular immune responses during IC provides a valuable tool for defining the contribution of different innate immune cells in host defense and immunopathology in various Candida-infected tissues using isolated or combined cell depletion strategies in vivo.

In summary, we have defined the temporal and spatial dynamics of the cellular immune response in the blood and four major organs of mice infected fatally and systemically with C. albicans. Our results demonstrate effective and ineffective innate immune responses to this fungus in different organs within the same animal. These findings highlight the need for further research on organ-specific cellular and molecular factors that shape and modulate the immune response to infectious agents. This information may be important for understanding Candida pathogenesis in particular and mechanisms of host defense in general, and may provide new insights for improved treatment strategies against pathogens that exhibit tissue-specific tropisms.

\section{Acknowledgment}

This research was supported by the Division of Intramural Research of the National Institute of Allergy and Infectious Diseases, National Institutes of Health.

\section{Disclosure Statement}

The authors do not have a commercial or other association that might pose a conflict of interest.

\section{References}

$>1$ Zaoutis TE, Argon J, Chu J, Berlin JA, Walsh TJ, Feudtner C: The epidemiology and attributable outcomes of candidemia in adults and children hospitalized in the United States: a propensity analysis. Clin Infect Dis 2005;41:1232-1239.

2 Papadimitriou JM, Ashman RB: The pathogenesis of acute systemic candidiasis in a susceptible inbred mouse strain. J Pathol 1986 150:257-265.

-3 Spellberg B, Ibrahim AS, Edwards JE Jr, Filler SG: Mice with disseminated candidiasis die of progressive sepsis. J Infect Dis 2005; 192:336-343.

-4 MacCallum DM, Odds FC: Need for early antifungal treatment confirmed in experimental disseminated Candida albicans infection. Antimicrob Agents Chemother 2004;48:4911-4914.
5 Fulurija A, Ashman RB, Papadimitriou JM: Neutrophil depletion increases susceptibility to systemic and vaginal candidiasis in mice, and reveals differences between brain and kidney in mechanisms of host resistance. Microbiology 1996;142:3487-3496.

-6 Romani L, Mencacci A, Cenci E, Del Sero G, Bistoni F, Puccetti P: An immunoregulatory role for neutrophils in CD4+ Thelper subset selection in mice with candidiasis. J Immunol 1997;158:2356-2362.

-7 Qian Q, Jutila MA, Van Rooijen N, Cutler JE: Elimination of mouse splenic macrophages correlates with increased susceptibility to experimental disseminated candidiasis. J Immunol 1994;152:5000-5008.

-8 Vázquez-Torres A, Balish E: Macrophages in resistance to candidiasis. Microbiol Mol Biol Rev 1997;61:170-192.
9 Mahanty S, Greenfield RA, Joyce WA, Kincade PW: Inoculation candidiasis in a murine model of severe combined immunodeficiency syndrome. Infect Immun 1988;56: 3162-3166.

10 Schuit KE: Phagocytosis and intracellular killing of pathogenic yeasts by human monocytes and neutrophils. Infect Immun 1979; 24:932-938.

- 11 Tsou CL, Peters W, Si Y, Slaymaker S, Slaymaker S, Aslanian AM, et al: Critical roles for CCR2 and MCP-3 in monocyte mobilization from bone marrow and recruitment to inflammatory sites. J Clin Invest 2007;117: 902-909.

12 Sanos SL, Bui VL, Mortha A, Oberle K, Heners C, Johner C, et al: ROR $\gamma$ t and commensal microflora are required for the differentiation of mucosal interleukin 22-producing NKp46+ cells. Nat Immunol 2009;10:83-91. 
-13 Kanazawa H, Ohsawa K, Sasaki Y, Kohsaka S, Imai Y: Macrophage/microglia-specific protein Ibal enhances membrane ruffling and Rac activation via phospholipase C- $\gamma$ dependent pathway. J Biol Chem 2002;277: 20026-20032.

14 Glass WG, Lim JK, Cholera R, Pletnev AG, Gao JL, Murphy PM: Chemokine receptor CCR5 promotes leukocyte trafficking to the brain and survival in West Nile virus infection. J Exp Med 2005;202:1087-1098.

15 Salazar-Mather TP, Hamilton TA, Biron CA: A chemokine-to-cytokine-to-chemokine cascade critical in antiviral defense. J Clin Invest 2000;105:985-993.

-16 Sarin SK, Sabba C, Groszmann RJ: Splanchnic and systemic hemodynamics in mice using a radioactive microsphere technique. Am J Physiol 1990;258:G365-G369.

17 Lo HJ, Köhler JR, DiDomenico B, Loebenberg D, Cacciapuoti A, Fink GR: Nonfilamentous C. albicans mutants are avirulent. Cell 1997;90:939-949.

18 Sudbery P, Gow N, Berman J: The distinct morphogenic states of Candida albicans. Trends Microbiol 2004;12:317-324.

19 Blasi E, Mazzolla R, Barluzzi R, Mosci P, Bartoli A, Bistoni F: Intracerebral transfer of an in vitro established microglial cell line: local induction of a protective state against lethal challenge with Candida albicans. J Neuroimmunol 1991;32:249-257.

20 Lawson LJ, Perry VH, Gordon S: Turnover of resident microglia in the normal adult mouse brain. Neuroscience 1992;48:405-415.

-21 Garey KW, Rege M, Pai MP, Mingo DE, Suda KJ, Turpin RS, et al: Time to initiation of fluconazole therapy impacts mortality in patients with candidemia: a multi-institutional study. Clin Infect Dis 2006;43:25-31.
22 Saville SP, Lazzell AL, Chaturvedi AK, Monteagudo C, Lopez-Ribot JL: Use of a genetically engineered strain to evaluate the pathogenic potential of yeast cell and filamentous forms during Candida albicans systemic infection in immunodeficient mice. Infect Immun 2008;76:97-102.

23 Cutler JE, Poor AH: Effect of mouse phagocytes on Candida albicans in in vivo chambers. Infect Immun 1981;31:1110-1116.

24 Diamond RD, Krzesicki R, Jao W: Damage to hyphal forms of Candida albicans by neutrophils in the absence of serum in vitro. J Clin Invest 1978;61:349-359.

25 Weiss SJ: Tissue destruction by neutrophils N Engl J Med 1989;320:365-376.

-26 Gargan RA, Hamilton-Miller JM, Brumfitt W: Effect of $\mathrm{pH}$ and osmolality on in vitro phagocytosis and killing by neutrophils in urine. Infect Immun 1993:61:8-12.

27 Naglik J, Albrecht A, Bader O, Hube B: Candida albicans proteinases and host/pathogen interactions. Cell Microbiol 2004;6:915-926.

28 Krause PJ, Malech HL, Kristie J, Kosciol CM, Herson VC, Eisenfeld L, et al: Polymorphonuclear leukocyte heterogeneity in neonates and adults. Blood 1986;68:200-204.

29 Tsuda Y, Takahashi H, Kobayashi M, Hanafusa T, Herndon DN, Suzuki F: Three different neutrophil subsets exhibited in mice with different susceptibilities to infection by methicillin-resistant Staphylococcus aureus. Immunity 2004;21:215-226.

30 Mencacci A, Montagnoli C, Bacci A, Cenci E, Pitzurra L, Spreca A, et al: CD80+Gr-1+ myeloid cells inhibit development of antifungal Th1 immunity in mice with candidiasis. J Immunol 2002;169:3180-3190.
31 Romani L, Mencacci A, Cenci E, Spaccapelo R, Del Sero G, Nicoletti I, et al: Neutrophil production of IL-12 and IL-10 in candidiasis and efficacy of IL-12 therapy in neutropenic mice. J Immunol 1997;158:5349-5356.

32 Redmond HP, Shou J, Gallagher HJ, Kelly CJ, Daly JM: Macrophage-dependent candidacidal mechanisms in the murine system. Comparison of murine Kupffer cell and peritoneal macrophage candidacidal mechanisms. J Immunol 1993;150:3427-3433.

33 Serbina NV, Jia T, Hohl TM, Pamer EG: Monocyte-mediated defense against microbial pathogens. Annu Rev Immunol 2008;26: 421-452.

34 Getts DR, Terry RL, Getts MT, Müller M, Rana S, Shrestha B, et al: Ly6c+ 'inflammatory monocytes' are microglial precursors recruited in a pathogenic manner in West Nile virus encephalitis. J Exp Med 2008;205: 2319-2337.

-35 Romani L, Mencacci A, Cenci E, Spaccapelo R, Schiaffella E, Tonnetti L, et al: Natural killer cells do not play a dominant role in CD4+ subset differentiation in Candida albicans-infected mice. Infect Immun 1993;61: 3769-3774.

36 Algarra I, Ortega E, Serrano MJ, Alvarez de Cienfuegos G, Gaforio JJ: Suppression of splenic macrophage Candida albicans phagocytosis following in vivo depletion of natural killer cells in immunocompetent BALB/c mice and T-cell-deficient nude mice. FEMS Immunol Med Microbiol 2002;33:159-163.

-37 d'Ostiani CF, Del Sero G, Bacci A, Montagnoli C, Spreca A, Mencacci A, et al: Dendritic cells discriminate between yeasts and hyphae of the fungus Candida albicans. Implications for initiation of $\mathrm{T}$ helper cell immunity in vitro and in vivo. J Exp Med 2000;191:1661-1674. 